\title{
A Comprehensive Review on Factors Influences Biogenesis, Functions, Therapeutic and Clinical Implications of Exosomes
}

This article was published in the following Dove Press journal: International Journal of Nanomedicine

\author{
Sangiliyandi Gurunathan \\ Min-Hee Kang (D) \\ Jin-Hoi Kim (D)
}

Department of Stem Cell and Regenerative Biotechnology, Konkuk University, Seoul, 05029, Korea
Correspondence: Sangiliyandi

Gurunathan; Jin-Hoi Kim

Department of Stem Cell and Regenerative Biotechnology, Konkuk

University, Seoul, 05029, Korea

Tel +82 24503687

Fax +82 25444645

Email gsangiliyandi@yahoo.com;

jhkim54I@konkuk.ac.kr

\begin{abstract}
Exosomes are nanoscale-sized membrane vesicles secreted by almost all cell types into the extracellular environment upon fusion of multivesicular bodies and plasma membrane. Biogenesis of exosomes is a protein quality control mechanism, and once released, exosomes transmit signals to other cells. The applications of exosomes have increased immensely in biomedical fields owing to their cell-specific cargos that facilitate intercellular communications with neighboring cells through the transfer of biologically active compounds. The diverse constituents of exosomes reflect their cell of origin and their detection in biological fluids represents a diagnostic marker for various diseases. Exosome research is expanding rapidly due to the potential for clinical application to therapeutics and diagnosis. However, several aspects of exosome biology remain elusive. To discover the use of exosomes in the biomedical applications, we must better understand the basic molecular mechanisms underlying their biogenesis and function. In this comprehensive review, we describe factors involved in exosomes biogenesis and the role of exosomes in intercellular signaling and cell-cell communications, immune responses, cellular homeostasis, autophagy, and infectious diseases. In addition, we discuss the role of exosomes as diagnostic markers, and their therapeutic and clinical implications. Furthermore, we addressed the challenges and outstanding developments in exosome research, and discuss future perspectives.
\end{abstract}

Keywords: extracellular vesicle, exosome, biogenesis, function, cell-cell communication, immune response, cellular homeostasis, autophagy

\section{Introduction}

Extracellular vesicles (EVs) including exosomes, microvesicles, and apoptotic bodies are produced and released by almost all types of cell. EVs vary in size, properties, and secretion pathway depending on the originating cell. ${ }^{1,2}$ Exosomes are small EVs (sEVs) which are formed by a process of inward budding in early endosomes to form multivesicular bodies (MVBs) with an average size of $100 \mathrm{~nm}$, and released into the extracellular microenvironment to transfer their components. $^{3,4}$ Microvesicles are composed of lipid components of the plasma membrane and their sizes range from 100-1000 nm, whereas apoptotic bodies result from programmed cell death. ${ }^{5}$ Initially, EVs were considered to maintain cellular waste through release of unwanted proteins and biomolecules; later, these organelles were considered important for intercellular communications through various cargo molecules such as lipids, proteins, DNA, RNA, and microRNAs 
(miRNAs). ${ }^{6}$ Previously, it was suggested that EVs play a critical role in normal cells to maintain homeostasis and prevent cancer initiation. Inhibition of EVs secretion causes accumulation of nuclear DNA in the cytoplasm, leading to apoptosis. ${ }^{1}$ The induction of apoptosis is the principal event of the reactive oxygen species (ROS) dependent DNA damage response. ${ }^{7,8}$

Several studies reported that exosomes are synthesized by means of two major pathways, the endosomal sorting complexes required for transport (ESCRT)-dependent and ESCRT-independent, and the processes are highly regulated by multiple signal transduction cascades. ${ }^{1-8}$ Exosomes released from the cell through normal exocytosis mechanisms are characterized by vesicular docking and fusion with the aid of SNARE complexes. Exosomes are considered to be organelle responsible for garbage disposal agents. However, at a later stage, these secretory bodies play a critical role in maintaining the physiological and pathological conditions of the surrounding cells by transferring information from donor cells to recipient cells. Exosome development begins with endocytosis to form early endosomes, later forming multivesicular endosomes (MVEs), and finally generating late endosomes by inward budding. MVEs merge with the cell membrane and release intraluminal endosomal vesicles that become exosomes into the extracellular space. ${ }^{9,10}$ Exosome biogenesis is dependent on various critical factors including the site of biogenesis, protein sorting, physicochemical aspects, and transacting mediators. ${ }^{11}$

Exosomes contain various types of cargo molecules including lipids, proteins, DNAs, mRNAs, and miRNAs. Most of the cargo is involved in the biogenesis and transportation ability of exosomes. ${ }^{12,13}$ Exosomes are released by fusion of MVBs with the cell membrane via activation of Rab-GTPases and SNAREs. Exosomes are abundant and can be isolated from a wide variety of body fluids and also cell culture medium. ${ }^{14}$ Exosomes contain tetraspanins that are responsible for cell penetration, invasion, and fusion events. Exosomes are released onto the external surface by the MVB formation proteins Alix and TSG101. Exosome-bound proteins, annexins and Rab protein, govern membrane transport and fusion whereas Alix, flotillin, and TSG101 are involved in exosome biogenesis. ${ }^{15,16}$ Exosomes contain various types of proteins such as integral exosomal membrane proteins, lipid-anchored outer and inner membrane proteins, peripheral surface and inner membrane proteins, exosomal enzymes, and soluble proteins that play critical roles in exosome functions. ${ }^{11}$
The functions of exosomes depend on the origin of the cell/tissue, and are involved in the immune response, antigen presentation programmed cell death, angiogenesis, inflammation, coagulation, and morphogen transporters in the creation of polarity during development and differentiation. ${ }^{17-20}$ Ferguson and Nguyen reported that the unique functions of exosomes depend on the availability of unique and specific proteins and also the type of cell. ${ }^{21}$ All of these categories influence cellular aspects of proteins such as the cell junction, chaperones, the cytoskeleton, membrane trafficking, structure, and transmembrane receptor/regulatory adaptor proteins. The role of exosomes has been explored in different pathophysiological conditions including metabolic diseases. Exosomes are extremely useful in cancer biology for the early detection of cancer, which could increase prognosis and survival. For example, the presence of CD24, EDIL3, and fibronectin proteins on circulating exosomes has been proposed as a marker of early-stage breast cancer. ${ }^{22}$ Cancer-derived exosomes promoted tumor growth by directly activating the signaling pathways such as P13K/AKT or MAPK/ ERK. $^{23}$ Tumor-derived exosomes are significantly involved in the immune system, particularly stimulating the immune response against cancer and delivering tumor antigens to dendric cells to produce exosomes, which in turn stimulates the T-cell-mediated antitumor immune response. $^{24}$ Exosomal surface proteins are involved in immunotherapies through the regulation of the tumor immune microenvironment by aberrant cancer signaling. ${ }^{25}$ A study demonstrated that exosomes have the potential to affect health and pathology of cells through contents of the vesicle. ${ }^{26}$ Exosomes derived from mesenchymal stem cells exhibit protective effects in stroke models following neural injury resulting from middle cerebral artery occlusion. ${ }^{27}$ The structural region of the exosome facilitate the release of misfolded and prion proteins, and are also involved in the propagation of neurodegenerative diseases such as Huntington disease, Alzheimer's disease (AD), and Parkinson's disease (PD). ${ }^{28,29}$

Exosomes serve as novel intercellular communicators due to their cell-specific cargo of proteins, lipids, and nucleic acids. In addition, exosomes released from parental cells may interact with target cells, and it can influence cell behavior and phenotype features ${ }^{30}$ and also it mediate the horizontal transfer of genetic material via interaction of surface adhesion proteins. ${ }^{31}$ Exosomes are potentially serving as biomarkers due to the wide-spread and cellspecific availability of exosomes in almost all body 
fluids. $^{13}$ Therefore, exosomes are exhibited as delivery vehicles for the efficient delivery of biological therapeutics across different biological barriers to target cells. ${ }^{32-34}$

In this review, first, we comprehensively describe the factors involved in exosome biogenesis and the role of exosomes in intercellular signaling and cell-cell communications, immune responses, cellular homeostasis, autophagy, and infectious diseases. In addition, we discuss the role of exosomes as diagnostic markers, and the therapeutic and clinical implications. Finally, we discuss the challenges and outstanding developments in exosome research.

\section{Factors Controlling the Biogenesis of Exosomes}

The extracellular vesicles play critical role in inter cellular communication by serving as vehicles for transfer of biomolecules. These vesicles are generally classified into microvesicles, ectosomes, shedding vesicles, or microparticles. MVs bud directly from the plasma membrane, whereas exosomes are represented by small vesicles of different sizes that are formed as the ILV by budding into early endosomes and MVBs and are released by fusion of MVBs with the plasma membrane (Figure 1). Invagination of late endosomal membranes results in the formation of intraluminal vesicles (ILVs) within large MVBs. ${ }^{35}$ Biogenesis of exosomes occurs in three ways including vesicle budding into discrete endosomes that mature into multivesicular bodies, which release exosomes upon plasma membrane fusion; direct vesicle budding from the plasma membrane; and delayed release by budding at intracellular plasma membrane-connected compartments (IPMCs) followed by deconstruction of IPMC neck(s). ${ }^{11}$ The mechanisms of biogenesis of exosomes are governed by various types of proteins including the ESCRT proteins Hrs, CHMP4, TSG101, STAM1, VPS4, and other proteins such as the Syndecan-syntenin-ALIX complex, nSMase2, PLD2, and CD9. ${ }^{14,36-39}$ After formation, the MVB can either fuse with the lysosome to degrade its content or fuse with the plasma membrane to release the ILVs as exosomes. The release of exosomes to the extracellular milieu is driven by proteins of the Rab-GTPase family including RAB2B, 5A, 7, 9A, 11, 27, and 35. SNARE family proteins VAMP7 and YKT6 have also been implicated in the release. ${ }^{14,38,40-42}$ Biogenesis of exosomes is influenced by several external factors including cell type, cell confluency, serum conditions, and the presence and absence of cytokines and growth factors. In addition, biogenesis is also regulated by the sites of exosomes, protein sorting, physico-chemical aspects, and trans-acting mediators (Figure 2). For example, THP-1 cells were cultured in RPMI-1640 cell culture medium

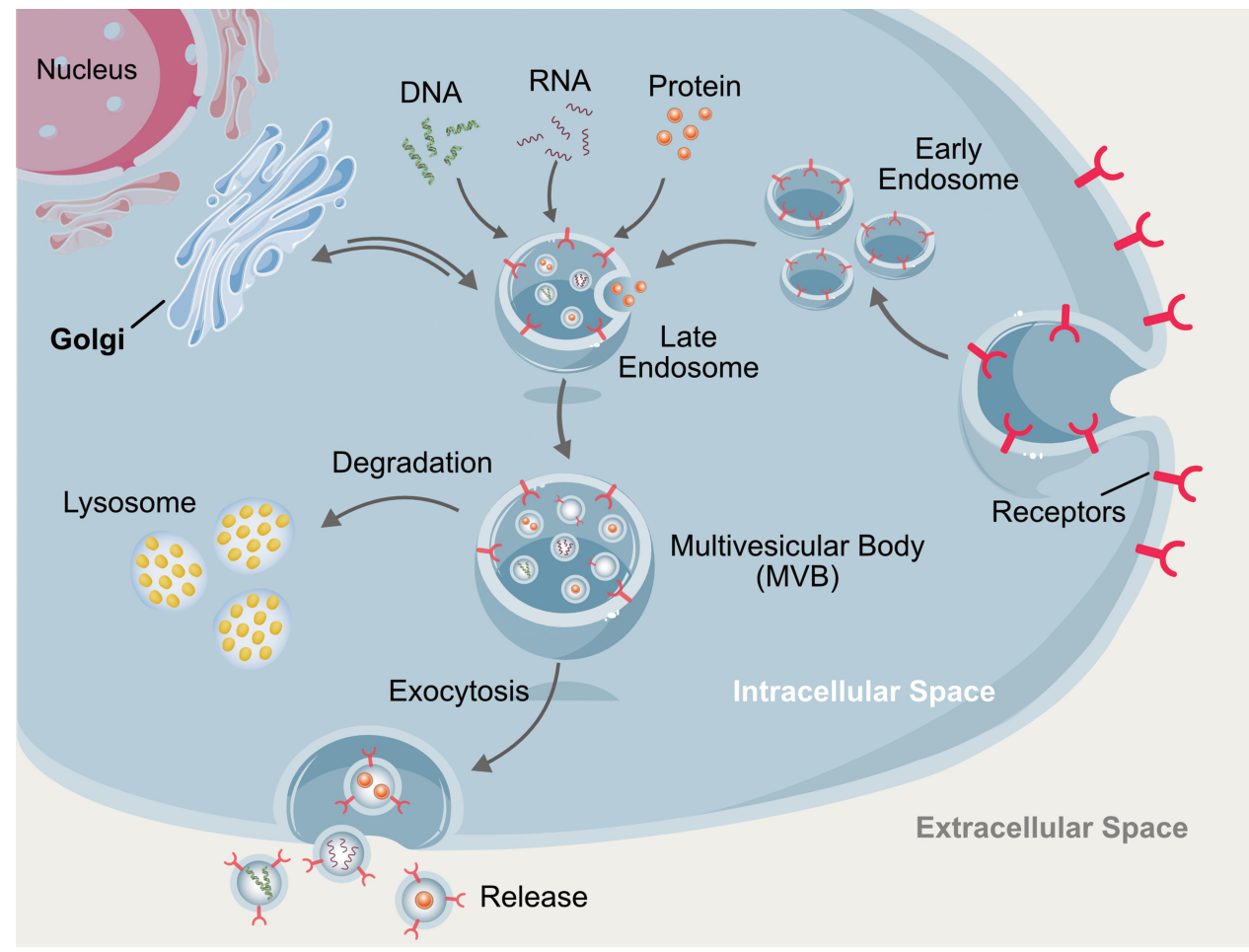

Figure I Biogenesis and cargoes of exosomes. 


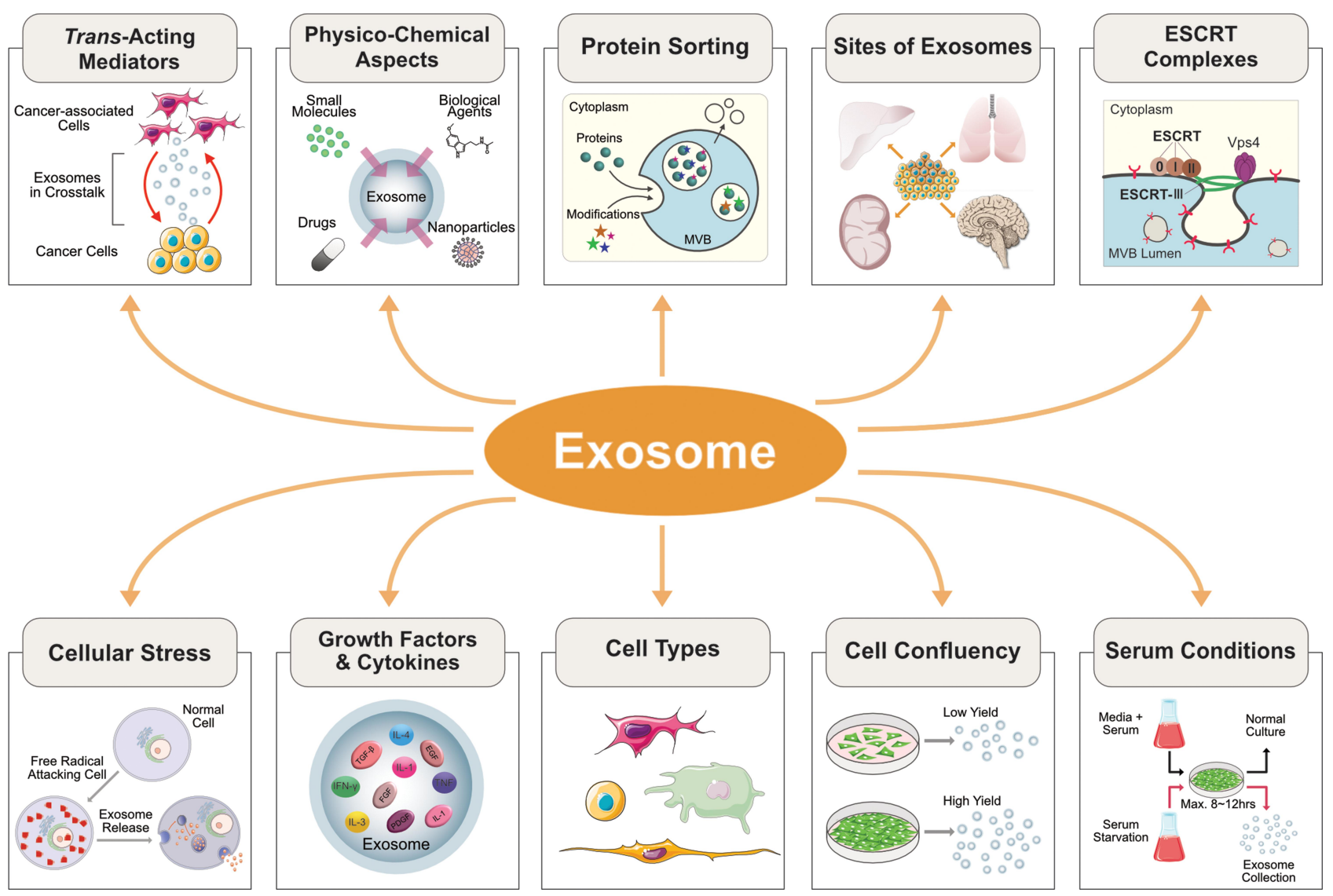

Figure 2 Effect of various factors on biogenesis of exosomes.

supplemented with $10 \%$ FCS secreted low level of exosomes compared to cells grown on cell culture medium supplemented with 1\% FCS (Figure 3). The exogenous factor like serum starvation influences biogenesis and secretion of exosomes.

Exosome release depends on expression of Rab27 or Ral. For example, exosomes released from the MVB significantly decrease in cells depleted of Rab $27^{41}$ or Ral. ${ }^{43}$
The most efficient EV-producing cell types have yet to be determined $^{44}$ and few reports suggest that immature dendritic cells produce limited amounts of $\mathrm{EVs}^{45,46}$ whereas mesenchymal stem cells secrete vast amounts, relevant for the production of EV therapeutics on a clinical scale. ${ }^{47,48}$ A few proteins play a critical role in the biogenesis of EVs, such as Rab27a and Rab27b. ${ }^{49}$ Over expression of Rab27a and Rab27b produce significant amounts of EVs
A

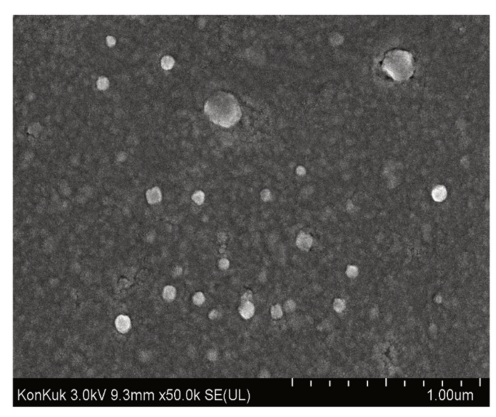

B

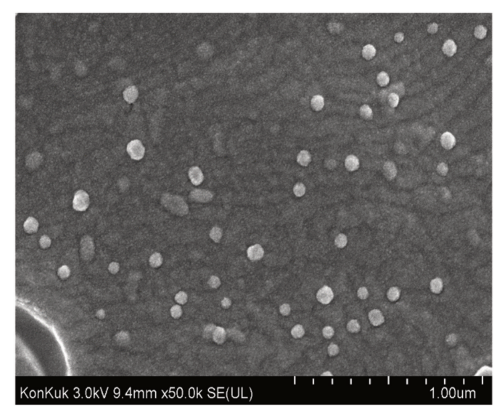

C

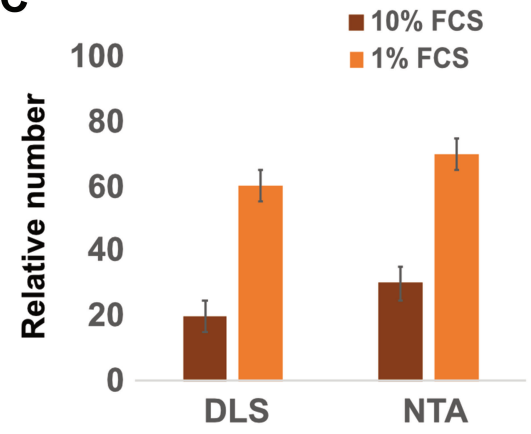

Figure 3 Serum deprivation causes an increase of the number of cellular exosomes in THP-I cells. Panel (A); I0\% FCS. Panel (B); I\% FCS. Panel (C) Quantification of exosomes using DLS and NTA. 
in cancer cells. For example, overexpression of Rab27a and Rab27b in breast cancer cells, ${ }^{50}$ hepatocellular carcinoma cells, ${ }^{51}$ glioma cells, ${ }^{52}$ and pancreas cancer cells ${ }^{53}$ produces significant levels of EVs. Although all types of cells secrete and release EVs, cancer cells seem to produce higher levels than normal cells. ${ }^{54}$ Furthermore, the presence of invadopodia that are docking sites for Rab27apositive MVBs induces secretion of $\mathrm{EVs}$, and also enhances secretion of EVs in cancer cells. ${ }^{55}$ Thus, inhibition of invadopodia formation greatly reduces exosome secretion into conditioned media. This evidence demonstrates that cancer cells potentially release more EVs than non-cancer cells.

The rate of origin of exosomes from the plasma membrane of stem cells is vigorous, at rates equal to the production of exosomes, ${ }^{56}$ which is consistent with a report suggesting that stem cells bud $\sim 50-100 \mathrm{~nm}-$ diameter vesicles directly from the plasma membrane. ${ }^{57}$ Plasma membrane-derived exosomes contain selectively enriched protein and lipid markers in leukocytes. ${ }^{58}$ Plasma membrane exosomal budding is also observed for glioblastoma exosomes. ${ }^{59}$ Conventional transmission electron microscopy revealed that certain cell types contain deep invaginations of the plasma membrane that are indistinguishable from MVBs. ${ }^{60-62}$ Certain cell types secrete exosomes containing cargo proteins, which primarily bud from the plasma membrane, and exosome composition is determined predominantly by intracellular protein trafficking pathways, rather than by the distinct mechanisms of exosome biogenesis. ${ }^{63}$ Biogenesis of exosomes is regulated by syndecan heparan sulphate proteoglycans and their cytoplasmic adaptor syntenin. Syntenin interacts directly with ALIX through LYPX (n) L motifs. ${ }^{64}$ Glycosylation is an essential factor in the biogenesis of exosomes and $\mathrm{N}$-linked glycosylation directs glycoprotein sorting into EMVs. ${ }^{65}$ Collectively, these reports suggest that exosomes are made at both plasma and endosome membranes rather than endosome alone. Oligomerization is a critical factor for exosomal protein sorting and it was found to be sufficient to target plasma membrane proteins to exosomes. High-order oligomeric proteins target them to exosomes. ${ }^{66}$ Further, plasma membrane anchors support exosomal protein budding. For example, budding of CD63 and CD9 from the plasma membrane is much more efficient than endosome-targeted budding of CD63 and CD9. ${ }^{63}$ Protein clustering is another factor that induces membrane scission. ${ }^{67}$
Physico-chemical properties determine budding efficiency and are crucial factors of exosome biogenesis, a fundamental process involving the budding of vesicles that are $30-200 \mathrm{~nm}$ in size. In particular, lipids are critical players in exosome biogenesis, especially those able to form cone and inverse cone shapes. Generally, exosome membranes contain phosphatidylcholine (PC), phosphatidylserine (PS), phosphatidylethanolamine (PE), phosphatidylinositols (PIs), phosphatidic acid (PA), cholesterol, ceramides, sphingomyelin, glycosphingolipids, and a number of lower abundance lipids. ${ }^{68,69}$ Exosomes have a rich content of PE and PS, which increase budding efficiency and promote exosome genesis and release. PA promotes exosome biogenesis and PLD2 is involved in the budding of certain exosomal cargoes. ${ }^{70}$ Besides these factors, ceramide is an important lipid molecule regulating exosome biogenesis and facilitating membrane curvature, which is essential for vesicular budding. Inhibition of an enzyme that generates ceramide impairs exosome biogenesis. $^{71}$

The next critical factor is trans-acting mediators that are involved in the biogenesis of exosomes through regulating plasma membrane homeostasis, intracellular protein trafficking pathways, MVB maturation and trafficking, IPMC biogenesis, vesicle budding, and scission. ${ }^{11}$ For example, Rab proteins regulate exosome biogenesis via endosomes and the plasma membrane by determining organelle membrane identity, recruiting mechanistic effectors, and mediating organelle dynamics. ${ }^{72}$ The functions of Rab proteins in the control and biogenesis of exosomes depends on cell type. MVB biogenesis is regulated by Rab27a, Rab27b, their effectors Slp4, Slac2b, and Munc13-4, and also Rab 35 and Rab 11. ${ }^{73}$ Loss of Rab27 function leads to a $\sim 50-75 \%$ drop in exosome production, and is also involved in assembling the plasma membrane microdomains involved in plasma membrane vesicle budding, by regulating plasma membrane PIP2 dynamics. ${ }^{74}$ Overall, Rab27 proteins control exosome biogenesis at both endosomes and plasma membranes. In addition, Rab35 also contributes to exosome biogenesis by regulating PIP2 levels of plasma membrane, and its loss leads to a reduction of exosome release by $\sim 50 \%{ }^{75}$ Gurunathan et $\mathrm{al}^{76}$ reported that yeast produces two classes of secretory vesicles, low density and high density, and dynamin and clathrin are required for the biogenesis of these two different types of vesicle.

The Ral family is involved in the biogenesis of exosomes, and inhibition of Ral causes an accumulation of 
MVBs near the plasma membrane and a $\sim 50 \%$ decrease in the vesicular secretion of exosomes and exosomal marker proteins. ${ }^{43}$ Ral GTPases function through various effectors proteins, including Arf6 and the phospholipase PLD2, which are involved in exosomal release of SDCs. ${ }^{37}$ The ESCRT complex machinery (0 through III) are involved in MVB biogenesis on a major level including membrane deformation, sealing, and repair during a wide array of processes. The major contributions of the ESCRT complex to the biogenesis of vesicles are the recognition and sequestration of ubiquitinated proteins to specific domains of the endosomal membrane via ubiquitin binding subunits of ESCRT-0. After interaction with the ESCRT-I and -II complexes, the total complex will then combine with ESCRT-III, a protein complex that is involved in promoting the budding process. Finally, following cleaving of the buds to form ILVs, the ESCRT-III complex separates from the MVB membrane using energy supplied by the sorting protein Vps4. ${ }^{77}$ In addition, other proteins such as Alix, which is associated with several ESCRT (TSG101 and CHMP4) proteins, are involved in endosomal membrane budding and abscission, as well as exosomal cargo selection via interaction with syndecan. ${ }^{39}$ Another important factor, autophagy, is critically involved in exosome secretion. Autophagy related (Atg) proteins coordinate initiation, nucleation, and elongation during autophagosome biogenesis in the presence of ESCRT-III components including CHMP2A and VPS4. For instance, the absence of Atg5 in cancer cells causes a reduction in exosome production. ${ }^{78}$ Conversely, CRISPR/Cas9-mediated knockout of Atg5 in neuronal cells increases the release of exosomes and exosome-associated prions from neuronal cells. $^{79}$

Exosomes play a critical role in the physiologic regulation of mammary gland development and are important mediators of breast tumorigenesis. ${ }^{80}$ Biogenesis of exosomes occurs in all cell types; however, production depends on cell type. For example, breast cancer cells (BCC) produce increased numbers of exosomes compared to normal mammary epithelial cells. Studies revealed that patients with $\mathrm{BC}$ have increased numbers of MVs in their blood. ${ }^{81}$ Kavanagh et al reported that several fold changes were observed from exosomes isolated from triple negative breast cancer (TNBC) chemoresistant therapeutic induced senescent (TIS) cells compared with control EVs. ${ }^{82}$ TIS cells release significantly more EVs compared with control cells, containing chemotherapy and key proteins involved in cell proliferation, ATP depletion, and apoptosis, and exhibit the senescence-associated secretory phenotype (SASP). Cannabidiol (CBD), inhibits exosome and microvesicle (EMV) release in three different types of cancer cells including prostate cancer (PC3), hepatocellular carcinoma (HEPG2), and breast adenocarcinoma (MDA-MB-231). All three different cell lines show variability in the release of exosomes in a dose-dependent manner. These variabilities are all due to mitochondrial function, including modulation of STAT3 and prohibitin expression. This study suggests that the anticancer agent CBD plays critical role in EMV biogenesis. ${ }^{83}$ Sulfisoxazole (SFX) inhibits sEV secretion from breast cancer cells through interference with endothelin receptor A (ETA) through the reduced expression of proteins involved in the biogenesis and secretion of $\mathrm{sEV}$, and triggers co-localization of multivesicular endosomes with lysosomes for degradation. ${ }^{84}$ Secreted EVs from human colorectal cancer cells contain 957 vesicular proteins. The direct protein interactions between cellular proteins play a critical role in protein sorting during EV formation. SRC signaling plays a major role in EV biogenesis, and inhibition of SRC kinase decreases the intracellular biogenesis and cell surface release of EVs. ${ }^{85}$ Proteomic analysis revealed that the exosomes released from imatinibsensitive GIST882 cell line exhibit 764 proteins. The authors found that significant amount of proteins belong to protein release function and involved in the classical pathway and overlap to a high degree with proteins of exosomal origin. ${ }^{86}$ Exosomes secreted by antigenpresenting cells contain high levels of MHC class II proteins and costimulatory proteins, whereas exosomes released from other cell types lack these proteins. ${ }^{1,87}$

The biogenesis of exosomes depends on a percentage of confluency of approximately 60-90\%, which influences the yield and functions of EVs. ${ }^{44} \mathrm{Gal}$ et $\mathrm{al}^{88}$ observed a 10-fold decreased level of cholesterol metabolism in confluent cell cultures compared to cells in the preconfluent state. The high level of cholesterol content in confluent cells leads to a decreased level of EVs in prostate cancer. ${ }^{68}$ The major reason behind for the reduced level of vesicle production is contact inhibition, which triggers confluent cells to enter quiescence and/or alters their characteristics compared to actively dividing cells. ${ }^{89,90}$ Exogenous stimulation could influence the condition of the cells including the phenotype and efficacy of secretion. Previously, several studies demonstrated that various external factors increase biogenesis of EVs such as $\mathrm{Ca}^{2+}$ ionophores, ${ }^{91}$ hypoxia, $^{92-94}$ and detachment of cells, ${ }^{95}$ whereas 
lipopolysaccharide reduces biogenesis and release of EVs. ${ }^{96}$ Furthermore, serum, which supports adherence of the cells, plays a critical role in the biogenesis of EVs. ${ }^{97}$ For example, FCS has noticeable effects on cultured cells; however, the effects depend on cell type and differentiation status. ${ }^{97,98}$ To avoid the immense amounts of vesicles present in FCS, the use of conditioned media has been suggested. Culture viability and health status of cells are important aspects for producing an adequate amount of vesicles with proper cargo molecules such as protein and RNA. ${ }^{99,100}$ Exogenous stress, such as starvation, can induce phenotypic alterations and changes in proliferation. These changes cause alterations in the cell's metabolism and eventually lead to low yields. ${ }^{101,102}$

Cellular stresses, such as hypoxia, inflammation, and hyperglycemia, influence the RNA and protein content in exosomes. To examine these factors, the effects of cellular stresses on endothelial cells were studied. ${ }^{99}$ Endothelial cells were exposed to different types of cellular stress such as hypoxia, tumor necrosis factor- $\alpha$ (TNF- $\alpha$ )induced activation, and high glucose and mannose concentrations. The mRNA and protein content of exosomes produced by these cells were compared using microarray analysis and a quantitative proteomics approach. The results indicated that endothelial cell-derived exosomes contain 1354 proteins and 1992 mRNAs. Several proteins and mRNAs showed altered levels after exposure of their producing cells to cellular stress. Interestingly, cells exposed to high sugar concentrations had altered exosome protein composition only to a minor extent, and exosome RNA composition was not affected. Low-intensity ultrasound-induced (LIUS) anti-inflammatory effects have been achieved by upregulation of extracellular vesicle/ exosome biogenesis. These exosomes carry antiinflammatory cytokines and anti-inflammatory microRNAs, which inhibit inflammation of target cells via multiple shared and specific pathways. A study suggested that exosome-mediated anti-inflammatory effects of LIUS are feasible and that these techniques are potential novel therapeutics for cancers, inflammatory disorders, tissue regeneration, and tissue repair. ${ }^{103}$ Another factor, called manumycin-A (MA), a natural microbial metabolite, was analyzed in exosome biogenesis and secretion in castration-resistant prostate cancer (CRPC) C4-2B, cells. The effect of MA on cell growth was observed, and the results revealed that there was no effect on cell growth. However, MA attenuated the ESCRT-0 proteins Hrs, ALIX, and Rab27a, and exosome biogenesis and secretion by CRPC cells. The inhibitory effect of MA on exosome biogenesis and secretion was primarily mediated via targeted inhibition of Ras/Raf/ERK1/2 signaling. These findings suggest that MA is a potential drug candidate for the suppression of exosome biogenesis and secretion by CRPC cells. ${ }^{104}$

Methods of isolation of exosomes play critical roles in functions and delivery. Although several methods such as ultracentrifugation, density gradient centrifugation, chromatography, filtration, polymer-based precipitation, and immunoaffinity have been adopted to isolate pure exosomes without contamination, there is still a lack of consistency and agreement. ${ }^{105}$ Isolation of exosomes along with non-exosomal materials and damaged exosomal membranes creates artifacts and alters the protein and RNA profiles. Since exosomes are obtained from a variety of sources, the composition of proteins/lipids influences the sedimentation properties and isolation. Thus, precise and consistent techniques are warranted for the isolation, purification, and application of exosomes.

\section{Bio-Functions of Exosomes Intercellular Signaling and Cell-Cell Communications}

Although several functions of exosomes have been explored, the precise function of exosomes remains a mystery. Historically, exosomes have been known to function as cellular garbage bags, recyclers of cell surface proteins, cellular signalers, intercellular signaling and cellcell communications, immune responses, cellular homeostasis, autophagy, and infectious diseases. ${ }^{106}$ (Figure 4) ECVs are secreted cell-derived membrane particles involved in intercellular signaling and cell-cell communications, and contain immense bioactive information. Most cell types produce exosomes and release these into the extracellular environment, circulating through different bodily fluids such as urine, blood, and saliva and transferring their cargo to recipient cells. These vesicles play a significant role in various pathological conditions, such as different types of cancer, neurodegenerative diseases, infectious diseases, pregnancy complications, obesity, and autoimmune diseases, as reviewed elsewhere. ${ }^{107}$ Exosomes play a significant role in intercellular communication between cells by interacting with target cells via endocytosis. ${ }^{108}$ More specifically, exosomes are involved in cancer development, survival and metastasis of tumors, drug resistance, remodeling of the extracellular matrix, 


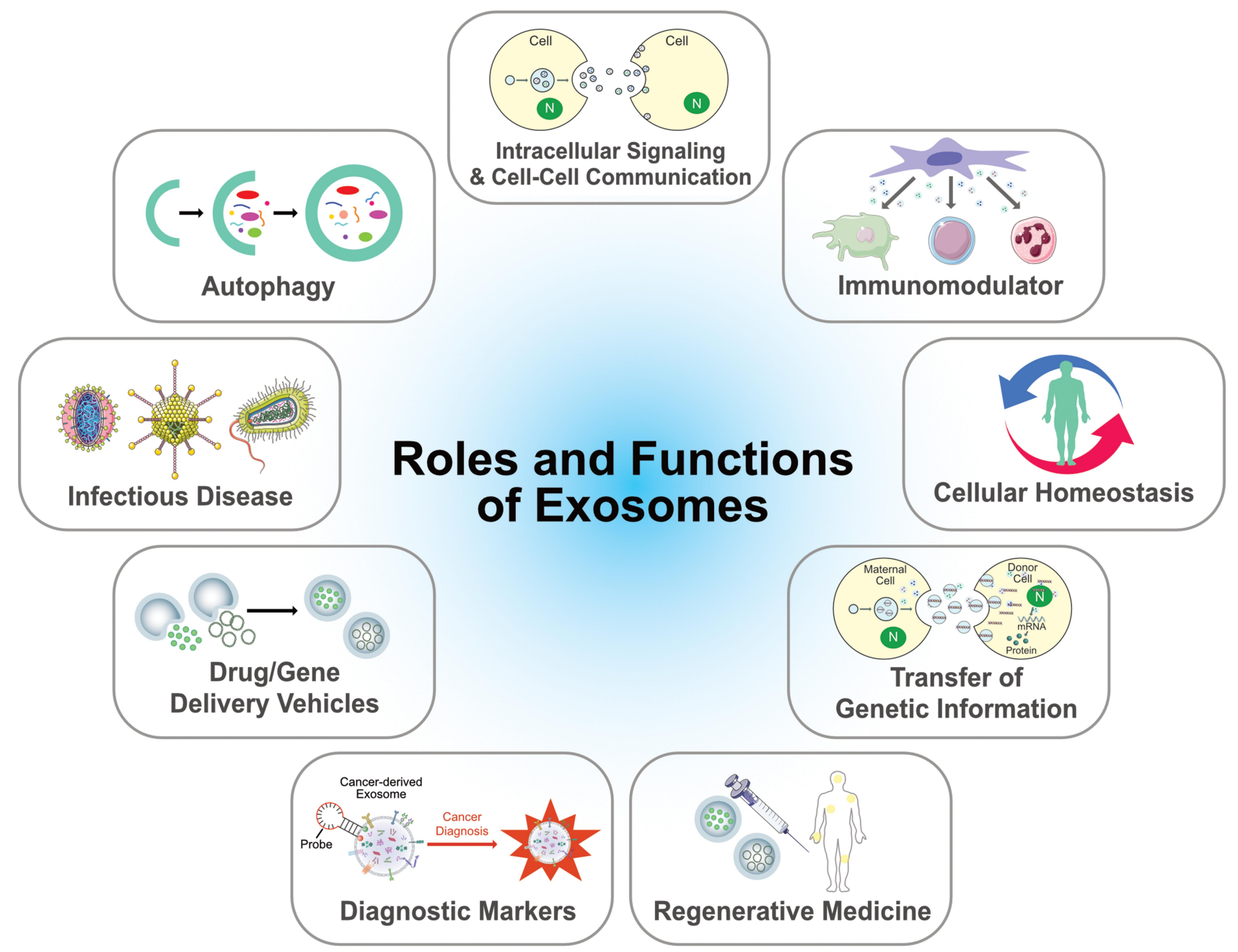

Figure 4 Multifunctional aspects biological functions of exosomes.

angiogenesis, thrombosis, and proliferation of tumor cells. ${ }^{94,109-111}$ Exosomes contribute significantly to tumor vascularization and hypoxia-mediated inter-tumor communication during cancer progression, and premetastatic niches, which are significant players in cancer. ${ }^{16,94,109,112}$ Exosomes derived from hepatic epithelial cells increase the expression of enhancer zeste homolog 2 (EZH2) and cyclin-D1, and subsequently promotes G1/S transition. ${ }^{113}$

Conventionally, cells communicate with adjacent cells through direct cell-cell contact through gap junctions and cell surface protein/protein interactions, whereas cells communicating with distant cells do so through secreted soluble factors, such as hormones and cytokines, to facilitate signal propagation. ${ }^{114}$ Cells also communicate through electrical and chemical signals. ${ }^{115}$ Several studies have suggested that exosomes play vital roles in intercellular communication by serving as vehicles for transferring various cellular constituents, such as proteins, lipids, and nucleic acids, between cells. ${ }^{6,116-118}$ Exosomes function as "exosomal shuttle RNAs" in which some exosomal RNAs from donor cells functions in recipient cells, ${ }^{6}$ a form of genetic exchange. Recently, researchers found that cells communicating with other cells through exosomes carrying cell-specific cargoes of proteins, lipids, and nucleic acids may employ novel intercellular communication mechanisms. ${ }^{30}$ Exosomes exert influences through various mechanistic approaches, such as direct stimulation of target cells via surface-bound ligands; transfer of activated receptors to recipient cells; and epigenetic reprogramming of recipient cells. ${ }^{119,120}$ Exosomes play critical roles in immunoregulation, including antigen presentation, immune activation, immune suppression, and immune tolerance via exosome-mediated intercellular communication. Mesenchymal stem cell (MSC)-derived exosomes play significant roles in wound healing processes. ${ }^{121}$ Exosomes from platelet-rich plasma (PRP) 
inhibit the release of TNF- $\alpha$. PRP-Exos significantly decreases the apoptotic rate of osteoarthritis (OA) chondrocytes compared with activated PRP (PRP-As). ${ }^{122}$ Extracellular vesicle (ECV)-modified polyethylenimine (PEI) complexes enhance short interfering RNA (siRNA) delivery by forming non-covalent complexes with small RNA molecules, including siRNAs and anti-miRs, in both conditions, in vitro and in vivo. ${ }^{123}$ Non-GSC glioma cells were treated with GSC-released exosomes. The results showed that GSC-released exosomes increase proliferation, neurosphere formation, invasive capacities, and tumorigenicity of non-GSC glioma cells through the Notch1 signaling pathway and stemness-related protein expressions. $^{124}$

Exosomal miR-1910-3p promotes proliferation and migration of breast cancer cells in vitro and in vivo through downregulation of myotubularin-related protein 3 and activation of the nuclear factor- $\mathrm{\kappa B}(\mathrm{NF}-\mathrm{\kappa B})$ and wnt/ $\beta$-catenin signaling pathway, and promotes breast cancer progression. ${ }^{125}$ Human hepatic progenitor cell $(\mathrm{CdH})$ derived exosomes (EXOhCdHs) play a crucial role in maintaining cell viability and inhibit oxidative stressinduced cell death. Experimental evidence suggests that inhibition of exosome secretion treatment with GW4869 results in the acceleration of reactive oxygen species (ROS) production, thereby causing a decrease in cell viability. ${ }^{126}$ Tumor-derived EXs (TDEs) are vehicles that enable communication between cells by transferring bioactive molecules, also delivering oncogenic molecules and containing different molecular cargoes compared to EXs delivered from normal cells. They can therefore be used as non-invasive biomarkers for the early diagnosis and prognosis of most cancers, including breast and ovarian cancers. ${ }^{127}$ Exosomes released by ER-stressed HepG2 cells significantly enhance the expression levels of several cytokines, including IL-6, monocyte chemotactic protein1 , IL-10, and tumor necrosis factor- $\alpha$ in macrophages. ER stress-associated exosomes mediate macrophage cytokine secretion in the liver cancer microenvironment, and also indicate the potential of treating liver cancer via an ER stress-exosomal-STAT3 pathway. ${ }^{128}$ Mesenchymal stem cell-derived exosomal miR-223 protects neuronal cells from apoptosis, enhances cell migration and increases miR-223 by targeting PTEN, thus activating the PI3K/ Akt pathway. In addition, exosomes isolated from the serum of AD patients promote cell apoptosis through the PTEN-PI3K/Akt pathway and these studies indicate a potential therapeutic approach for $\mathrm{AD} .{ }^{129} \mathrm{~A}$ mouse model of diabetes demonstrated that mesenchymal stromal cell-derived exosomes ameliorate peripheral neuropathy through increased nerve conduction velocity. In addition, MSC-derived exosomes substantially suppress proinflammatory cytokines. ${ }^{130}$

Exosomes derived from activated astrocytes promote microglial M2 phenotype transformation following traumatic brain injury (TBI). miR-873a-5p significantly inhibits LPS-induced microglial M1 phenotype transformation. ${ }^{131}$ Several studies reported that exosomes are involved in cancer progression and metastasis; however, this depends on the type of cells the exosomes were derived from. For example, human umbilical vein endothelial cells (HUVEC) were treated with exosomes derived from HeLa cells (ExoHeLa), and the expression of tight junctions (TJ) proteins, such as zonula occludens-1 (ZO-1) and Claudin-5, was significantly reduced compared with exosomes from human cervical epithelial cells. Thus, permeability of the endothelial monolayer was increased after the treatment with ExoHeLa. Mice studies have shown that injection of ExoHeLa into mice increased vascular permeability and tumor metastasis. The results from this study demonstrated that HeLa cell-derived exosomes promote metastasis by triggering ER stress in endothelial cells and break down endothelial integrity. Such effects of exosomes are microRNA-independent. ${ }^{132}$ Exosomes mediate the gene expression of target cells and regulate pathological and physiological processes including promoting angiogenesis, inhibiting ventricular remodeling and improving cardiac function, as well as inhibiting local inflammation and regulating the immune response. Accumulating evidence shows that exosomes possess therapeutic potential through their anti-apoptotic and anti-fibrotic roles.

\section{Exosomes and Immune Responses}

The functions of exosomes in immune responses are well established and do not cause any severe immune responses. A mouse study demonstrated that administration of a low dose of mouse or human cell-derived exosomes for extended periods of time caused no severe immune reactions. ${ }^{133}$ The function of exosomes in immune regulation is regulated by the transfer and presentation of antigenic peptides. Exosomes contain antigen-presenting cells (APCs) carrying peptide MHC-II and costimulatory signals and directly present the peptide antigen to specific T cells to induce their activation. ${ }^{134}$ For example, intradermal injection of APC-derived exosomes with MHC-II loaded with 
tumor peptide delayed tumor progression and growth. ${ }^{135}$ Exosome-derived immunogenic peptides activate immature mouse dendritic cells and indirectly activate APCs, and induce specific CD4+ $\mathrm{T}$ cell proliferation. ${ }^{136}$ Exosomes containing IFNa and IFNg, tumor necrosis factor a (TNFa), and IL from macrophages promoted dendritic cell maturation, CD4+ and CD8+ T cell activation, and the regulation of macrophage IL expression. ${ }^{137}$ The cargo of exosomes, such as DNA and miRNA, regulate the innate and adaptive immune responses. Exosomes are able to regulate the immune response by controlling gene expression and signaling pathways in recipient cells through transfer of miRNAs, and eventually control dendritic cell maturation. ${ }^{138}$ Exosomes containing miR-212-3p derived from tumors down-regulate the MHC-II transcription factor RFXAP (regulatory factor $\mathrm{X}$ associated protein) in dendritic cells, possibly promoting immune evasion by cancer cells. ${ }^{139}$ Exosomes containing miR-222-3p down regulate expression of SOCS3 (suppressor of cytokine signaling 3) in monocytes, which is involved in STAT3-mediated M2 polarization of macrophages. ${ }^{140}$ In mice, exosomes stimulate adaptive immune responses, including the activation of dendritic cells, with the uptake of breast cancer cell-derived exosomal genomic DNA and activation of cGAS-STING signaling and antitumor responses. ${ }^{141}$ The priming of dendritic cells is associated with the uptake of exosomal genomic and mitochondrial DNA (mtDNA) from $\mathrm{T}$ cells, inducing type I IFN production by cGAS-STING signaling. ${ }^{142}$ Inhibition of EGFR leads to increased levels of DNA in the exosomes and induces cGAS-STING signaling in dendritic cells, contributing to the overall suppression of tumor growth. ${ }^{143}$ Conversely, uptake of tumor-derived exosomal DNA by circulating neutrophils was shown to enhance the production of tissue factor and IL-8, which play a role in promoting tumor inflammation and paraneoplastic events. ${ }^{144}$ Melanoma-derived exosomes containing PD-L1 (programmed cell death ligand 1) suppress CD8+ $\mathrm{T}$ cell antitumor function and cancer cell-derived exosomes block dendritic cell maturation and migration in a PD-L1dependent manner. Engineered cancer cell-derived exosomes promote dendritic cell maturation, resulting in increased proliferation of $\mathrm{T}$ cells and antitumor activity. $^{145-147}$

Inflammation is an important process for maintaining homeostasis in cellular systems. Systemic inflammation is an essential component in the pathogenesis of several diseases. ${ }^{148,149}$ Exosomes seem to play a crucial role in inflammation processes through cargo molecules, such as
miRNA and proteins, which act on nearby as well as distant target tissues. Exosomes play a vital role in intercellular communication between cells via endocytosis and are associated with modulation of inflammation, coagulation, angiogenesis, and apoptosis. ${ }^{20,150-153}$ Exosomes derived from dendritic cells, B lymphocytes, and tumor cells release exosomes that can regulate immunological memory through the surface expression of antigenpresenting MHC I and MHC II molecules, and subsequently elicit $\mathrm{T}$ cell activation and maturation. ${ }^{134,137,154-156}$ Exosomes play a crucial role in carrying and presenting functional MHC-peptide complexes to modulate antigen-specific CD8+ and CD4+ responses. ${ }^{157,158}$ Exosomes containing miR-Let-7d influence the growth of T helper 1 (Th1) cells and inhibit IFN- $\gamma$ secretion. $^{159}$ Exosomes derived from choroid plexus epithelial cells containing miR-146a and miR-155 upregulate the expression of inflammatory cytokines in astrocytes and microglia. ${ }^{160}$ Exosomes containing miR-181c suppress the expression of Toll-like receptor 4 (TLR-4) and subsequently lower TNF- $\alpha$ and IL-1 $\beta$ levels in burninduced inflammation. ${ }^{161}$ Exosomal miR-155 from bone marrow cells (BMCs) increases the level of TNF- $\alpha$ and subsequently enhances innate immune responses in chronic inflammation. ${ }^{162}$ Exosomes containing miR-150$5 p$ and miR-142-3p derived from dendritic cells (DCs) increase expression of interleukin 10 (IL-10) and a decrease in IL-6 expression. ${ }^{163}$ Exosomal miR-138 can protect against inflammation by decreasing the expression level of NF- $\kappa \mathrm{B}$, a transcription factor that regulates inflammatory cytokines such as TNF- $\alpha$ and IL-18. ${ }^{164}$ HIF- $1 \alpha-$ inducing exosomal microRNA-23a expression from tubular epithelial cells mediates the cross talk between tubular epithelial cells and macrophages, promoting macrophage activation and triggering tubulointerstitial inflammation. ${ }^{165}$ A rat model study demonstrated that bone marrow mesenchymal stem cell (BMSC)-derived exosomes reduced inflammatory responses by modulating microglial polarization and maintaining the balance between M2related and M1-related cytokines. $^{165}$ Melatoninstimulated mesenchymal stem cell (MSC)-derived exosomes improve diabetic wound healing through regulating macrophage M1 and M2 polarization by targeting the PTEN/AKT pathway, and significantly suppressed the proinflammatory factors IL- $1 \beta$ and TNF- $\alpha$ and reduced the relative gene expression of IL-1 $\beta$, TNF- $\alpha$, and iNOS. Increasing levels of anti-inflammatory factor IL-10 are associated with increasing relative expression of Arg-1. ${ }^{166}$ 
Immunomodulators are essential factors for the prevention and treatment of disorders occurring due to an over high-spirited immune response, such as the SARS-CoV -2-triggered cytokine storm leading to lung pathology and mortality seen during the ongoing viral pandemic. ${ }^{167}$ MSC-secreted extracellular vesicles exhibit immunosuppressive capacity, which facilitates the regulation of the migration, proliferation, activation, and polarization of various immune cells, promoting a tolerogenic immune response while inhibiting inflammatory responses. ${ }^{168}$ Collagen scaffold umbilical cord-derived mesenchymal stem cell (UC-MSC)-derived exosomes induce collagen remodeling, endometrium regeneration, increasing the expression of the estrogen receptor $\alpha /$ progesterone receptor, and restoring fertility. Furthermore, exosomes modulate $\mathrm{CD} 163+\mathrm{M} 2$ macrophage polarization, reduce inflammation, increase anti-inflammatory responses, facilitate endometrium regeneration, and restore fertility through the immunomodulatory functions of miRNAs. ${ }^{169}$ Exosomes released into the airways during influenza virus infection trigger pulmonary inflammation and carry viral antigens and it facilitate the induction of a cellular immune response. ${ }^{170}$ Shenoy et $\mathrm{al}^{171}$ reported that exosomes derived from chronic inflammatory microenvironments contribute to the immune suppression of $\mathrm{T}$ cells. These exosomes arrest the activation of $\mathrm{T}$ cells stimulated via the $\mathrm{T}$ cell checkpoint (TCR). Exosomes secreted by normal retinal pigment epithelial cells (RPE) by rotenonestimulated ARPE-19 cells induce apoptosis, oxidative injury, and inflammation in ARPE-19 cells. Exosomes secreted under oxidative stress induce retinal function damage in rats and upregulate expression of Apaf1. Overexpression of Apaf1 in exosomes secreted under oxidative stress (OS) can cause the inhibition of cell proliferation, increase in apoptosis, and elicitation of inflammatory responses in ARPE-19 cells. Exosomes derived from ARPE-19 cells under OS regulate Apaf1 expression to increase apoptosis and to induce oxidative injury and inflammatory response through a caspase-9 apoptotic pathway. ${ }^{172}$ Collectively, these findings highlight the critical role of exosomes in inflammation and suggest the possibility of utilizing exosomes as an inducer to attenuate inflammation and restore impaired immune responses in various diseases including cancer.

\section{Exosomes and Cellular Homeostasis}

The endomembrane system of eukaryotic cells is a complex series of interconnected membranous organelles that play vital roles in protecting cells from adverse conditions, such as stress, and maintaining cell homeostasis during health and disease. ${ }^{173}$ To preserve cellular homeostasis, higher eukaryotic cells are equipped with various potent self-defense mechanisms, such as cellular senescence, which blocks the abnormal proliferation of cells at risk of neoplastic transformation and is considered to be an important tumor-suppressive mechanism. ${ }^{174,175}$ Exosomes contribute to reduce intracellular stress and preservation of cellular homeostasis through clearance of damaged or toxic material, including proteins, lipids, and even nucleic acids. Therefore, exosomes serve as quality controller in cells. ${ }^{176}$ The vesicular transport system plays pivotal roles in the maintenance of cell homeostasis in eukaryote cells, which involves the cytoplasmic trafficking of biomolecules inside and outside of cells. Several types of membrane-bound organelles, such as the Golgi apparatus, endoplasmic reticulum (ER), endosomes and lysosomes, in association with cytoskeleton elements, are involved in the intracellular vesicular system. Molecules are transported through exocytosis and endocytosis to maintain homeostasis through the intracellular vesicular system and regulate cells' responses to the internal and external environment. To maintain homeostasis and protect cells from various stress conditions, autophagy is an intracellular vesicular-related process that plays an important role through the endocytosis/lysosomal/exocytosis pathways through degradation and expulsion of damaged molecules out of the cytoplasm. ${ }^{177-179}$ Autophagy, as an intracellular waste elimination system, is a synchronized process that actively participates in cellular homeostasis through clearance and recycling of damaged proteins and organelles from the cytoplasm to autophagosomes, and then to lysosomes. ${ }^{38,180-182}$ Cells maintain homeostasis by autophagosomes, which are vesicles derived from autophagic and endosomal compartments. These processes are involved in adaption to nutrient deprivation, cell death, growth, and tumor progression or suppression. Autophagy flux contributes to maintaining homeostasis in the tumor microenvironment of endothelial cells. To support this concept, a study provided evidence suggesting that depletion of Atg5 in ECs could intensify the abnormal function of tumor vessels. ${ }^{183}$ Exosome secretion plays a crucial role in maintaining cellular homeostasis in exosome-secreting cells. As a consequence of blocking exosome secretion, nuclear DNA accumulates in the cytoplasm, thereby causing the activation of cytoplasmic DNA sensing machinery. Blocking exosome secretion 
aggravates the innate immune response, leading to ROSdependent DNA damage responses and thus inducing senescence-like cell-cycle arrest or apoptosis in normal human cells. Thus, cells remove harmful cytoplasmic DNA, protecting them from adverse effects. ${ }^{182}$ Salomon and Rice reported that the involvement of exosomes in placental homeostasis and pregnancy disorders. EVs of placental origin are found in a variety of body fluids including urine and blood. Moreover, the number of exosomes throughout gestation is higher in complications of pregnancy, such as preeclampsia and gestational diabetes mellitus, compared to normal pregnancies. ${ }^{184}$

The endolysosomal system is critically involved in maintaining homeostasis through the highly regulated processes of internalization, sorting, recycling, degradation, and secretion. For example, endocytosis allows the internalization of various receptor proteins into cells, and vesicles formed from the plasma membrane fuse and deliver their membrane and protein content to early endosomes. Similarly, significant amounts of internalized content are recycled back to the plasma membrane via recycling endosomes, ${ }^{76}$ while the remaining material is sequestered in ILVs in late endosomes, also known as multivesicular bodies. ${ }^{185,186}$ Tetraspanin proteins, such as CD63 and CD81, are regulators of ILV formation. Once ILVs are formed, MVBs can degrade their cargo by fusing with lysosomes or, alternatively, MVBs can secrete their ILVs by fusing with the plasma membrane and release their content into extracellular milieu. ${ }^{187-190}$ Exosomes play an important role in regulating intracellular RNA homeostasis by promoting the release of misfolded or degraded RNA products, and toxic RNA products. Y RNAs are involved in the degradation of structured and misfolded RNAs. Further studies have demonstrated that proteins involved in RNA processing are abundant in exosomes, and the half-lives of secreted RNAs are almost twice as short as those of intracellular mRNAs. These studies suggest that cells maintain intracellular RNA homeostasis through the release of distinct RNA species in extracellular vesicles. ${ }^{191-193}$ Exosomes reduce cholesterol accumulation in Niemann-Pick type $\mathrm{C}$ disease, a lysosomal storage disease in which cells accumulate unesterified cholesterol and sphingolipids within the endosomal and lysosomal compartment. ${ }^{194}$

\section{Exosomes and Autophagy}

Autophagy is the intracellular vesicular-related process that regulates the cell environment against pathological and stress conditions. In order to maintain homeostasis and protect the cells against stress conditions, internal vesicles or secreted vesicles serve as a canal to degrade and expel damaged molecules out of the cytoplasm. ${ }^{38,181,182}$ Autophagy protects the cell from various stress conditions and maintains cellular homeostasis, regulating cell survival and differentiation through clearance and recycling of damaged proteins and organelles from the cytoplasm to autophagosomes, and then to lysosomes. ${ }^{180}$ Several studies have demonstrated that proteins are involved in controlling tumor cell function and fate, and mediate crosstalk between exosome biogenesis and autophagy. Coordination between exosome-autophagy networks serves as a tool to conserve cellular homeostasis via the lysosomal degradative pathway and/or secretion of cargo into the extracellular milieu. ${ }^{176,195}$ Autophagy is a multi-step process that occurs by initiation, membrane nucleation, maturation and finally the fusion of autophagosomes with lysosomes. The autophagy process is not only linked with endocytosis but is also linked with the biogenesis of exosomes. For example, subsets of the autophagy machinery involved in the biogenesis of exosomes and the autophagic process itself appear dispensable. ${ }^{78,196}$ Crosstalk between exosomal and autophagic pathways has been reported in a growing number of diseases. Proteomic studies were performed to analyze the involvement of key proteins in the interconnection between exosome and autophagy pathways. They found that almost all proteins were identified; however, their involvement differed between them. Among 100 proteins, four proteins were highly ranked including HSPA8 (3/100), HSP90AA1 (8/100), VCP (24/100), and Rab7A (81/100). These data suggest an interconnection between the exosome and autophagy. ${ }^{197,198}$ Endosomal autophagy plays a significant role in the interconnection between exosomes and autophagy. Stress is a major factor for autophagy. In particular, the starvation of cells is a key inducer of autophagy, and induces enlargement of MVB structures and a co-localization of Rab11 and LC3 in these structures, an indication that autophagy-related processes are associated with the MVB. ${ }^{199}$ The sorting of autophagyrelated cargo into MVBs is dependent on Hsc70 (HSPA8), VPS4, and TSG101, and independent on LAMP-2A, thereby excluding a role for, the lysosome. ${ }^{200}$ Several proteins are involved in the regulation and biogenesis of secretory autophagy compartments such as GRASPs, LC3, Rab8a, ESCRTs, and SNAREs, along with several Atg proteins. ${ }^{181,201,202}$ Autophagosomes 
could fuse with MVBs to form amphisomes and release vesicles to the external environment. ${ }^{203}$

Autophagy and exosome biogenesis and function are interconnected by microRNA. Over-expression of miR221/222 inhibits the level of PTEN and activates Akt signaling, and subsequently reduces the expression of hallmarks that positively relate to autophagy including LC3 II, ATG5 and Beclin1, and increases the expression of SQSTM1/p62. ${ }^{204}$ MiR-221/222 from human aortic smooth muscle cell (HAoSMC)-derived exosomes inhibit autophagy in HUVECs by modulating the PTEN/Akt signaling pathway. miRNA-223 attenuates hypoxia-induced apoptosis and excessive autophagy in neonatal rat cardiomyocytes and $\mathrm{H} 9 \mathrm{C} 2$ cells via the Akt/mTOR pathway, by targeting poly(ADP-ribose) polymerase 1 (PARP-1) through increased autophagy via the AMPK/mTOR and Akt/mTOR pathways ${ }^{205}$ ATG5 mediates the dissociation of vacuolar proton pumps (V1Vo-ATPase) from MVBs, which prevents acidification of the MVB lumen and allows MVB-PM fusion and exosome release. Accordingly, knockout of ATG5 or ATG16L1 significantly reduces exosome release and attenuates the exosomal enrichment of lipidated LC3B. These findings demonstrate that autophagic mechanisms possibly regulate the fate of MVBs and subsequent exosome biogenesis. ${ }^{78}$ Bone marrow MSC (BMMSC)-derived exosomes contain a high level of miR-29c, which regulates autophagy under hypoxia/reoxygenation (H/R) conditions. ${ }^{206}$ Human umbilical cord MSC-derived exosomes (HucMDEs) promote hepatic glycolysis, glycogen storage, and lipolysis, and reduce gluconeogenesis. Additionally, autophagy potentially contributes to the effects of HucMDE treatment and increases formation of autophagosomes and the autophagy marker proteins BECN1, MAP, and 1LC3B. These findings suggest that HucMDEs improve hepatic glucose and lipid metabolism in T2DM rats by activating autophagy via the AMPK pathway. ${ }^{207}$ Liver fibrosis is a serious disorder caused by prolonged parenchymal cell death, leading to the activation of fibrogenic cells, extracellular matrix accumulation, and eventually liver fibrosis. Exosomes derived from adipose-derived mesenchymal stem cells (ADSCs) have been used to deliver circular RNAs mmu_circ_0000623 to treat liver fibrosis. The findings from this study suggest that Exos from ADSCs containing mmu_circ_0000623 significantly suppress CCl4-induced liver fibrosis by promoting autophagy activation. Autophagy inhibitor treatment significantly reverses the treatment effects of Exos. ${ }^{208}$ Inhibition of autophagy by PDGF and its downstream molecule SHP2 (Src homology 2-containing protein tyrosine phosphatase 2) increased hepatic stellate cell (HSC)-derived EV release. Disruption of mTOR signaling abolishes PDGF-dependent EV release. Activation of mTOR signaling induces the release of MVB-derived exosomes by inhibiting autophagy, as well as microvesicles, through activation of ROCK1 signaling. Furthermore, deletion of SHP2 attenuates CCl4 or BDLinduced liver fibrosis. ${ }^{209}$ The therapeutic effects of exosomes containing high concentrations of $\mathrm{mmu}_{-}$ circ_0000250 were analyzed in diabetic mice. The findings indicated that a high concentration of $\mathrm{mmu}_{-}$ circ_0000250 had a better therapeutic effect on wound healing when compared with wild-type exosomes from ADSCs. The results also showed that exosome treatment with mmu_circ_0000250 increased angiopoiesis in wounded skin and suppressed apoptosis by inducing miR-128-3p/SIRT1-mediated autophagy. ${ }^{210}$ A study showed that mice treated with differentiated cardiomyocyte (iCM) exosomes exhibited significant cardiac improvement post-myocardial infarction, with significantly reduced apoptosis and fibrosis. Apoptosis was associated with reduced levels of hypoxia and inhibition of exosome biogenesis. iCM-exosome-treated groups showed upregulation of autophagosome production and autophagy flux. Hence, these findings indicate that iCM-Ex can improve post-myocardial infarction cardiac function by regulating autophagy in hypoxic cardiomyocytes. ${ }^{211}$ Exosomes of hepatocytes play a crucial role in inhibiting hepatocyte apoptosis and promoting hepatocyte regeneration. Mesenchymal stem cell-derived hepatocyte-like cell exosomes (MSC-Heps-Exo) were injected into a mouse hepatic Ischemia/reperfusion (I/R) I/R model through the tail. The results demonstrated that MSC-Heps-Exo effectively relieve hepatic I/R damage, reduce hepatocyte apoptosis, and decrease liver enzyme levels. A possible mechanism of reduced hepatic ischemia/reperfusion injury is the enhancement of autophagy. ${ }^{212}$

\section{Exosome and Infectious Diseases}

Exosomes play a critical role in viral infections, particularly of retroviruses and retroviruses, and use preexisting pathways for intracellular protein trafficking and formation of infectious particles. Exosomes and viruses share several features including biogenesis, uptake by cells, and the intracellular transfer of RNAs, mRNAs, and cellular proteins. Some features are different, including selfreplication after infection of new cells, regulation of viral 
expression, and complex viral entry mechanisms. ${ }^{213,214}$ Exosomes secreted from virus-infected cells carry mostly cargo molecules such as viral proteins, genomic RNA, mRNA, miRNA, and genetic regulatory elements. ${ }^{215-218}$ These cargo molecules are involved in the alteration of recipient cell behavior, regulating cellular responses, and enabling infection by various types of viruses such as human T-cell lymphotropic virus (HTLV), hepatitis $\mathrm{C}$ virus (HCV), dengue virus, and human immunodeficiency virus (HIV). ${ }^{215}$ Exosomes communicate with host cells through contact between exosomes and their recipient cells, via different kinds of mechanisms. Initially, the transmembrane proteins of exosomes build a network directly with the signaling receptors of target cells and then join with the plasma membrane of recipient cells to transport their content to the cytosol. Finally, the exosomes are incorporated into the recipient cells. ${ }^{219-221} \mathrm{~A}$ report suggested that disruption of exosomal lipid rafts leads to the inhibition of internalization of exosomes. ${ }^{95}$ Exosomes derived from HIV-infected patients contain the transactivating response element, which is responsible for HIV-1 replication in recipient cells through downregulation of apoptosis. ${ }^{222}$ While exosomes serving as carrier molecules, exosomes contain miRNAs that induce viral replication and immune responses either by direct targeting of viral transcripts or through indirect modulation of virus-related host pathways. In addition, exosomes have been found to act as nanoscale carriers involved in HIV pathogenesis. For example, exosomes enhance HIV-1 entry into human monocytic and $\mathrm{T}$ cell lines through the exosomal tetraspanin proteins $\mathrm{CD} 9$ and $\mathrm{CD} 81 .^{223}$ Influenza virus infection causes accumulation of various types of microRNAs in bronchoalveolar lavage fluid, which are responsible for the potentiation of the innate immune response in mouse type II pneumocytes. Serum of influenza virus-infected mice show significant levels of miR-483-3p, which increases the expression of proinflammatory cytokine genes and inflammatory pathogenesis of $\mathrm{H} 5 \mathrm{~N} 1$ influenza virus infection in vascular endothelial cells. ${ }^{224}$ Exosomes are involved in the transmission of inflammatory, apoptotic, and regenerative signals through RNAs. Chen et al investigated the potential functions of exosomal RNAs by RNA sequencing analysis in exosomes derived from clinical specimens of healthy control (HC) individuals and patients with chronic hepatitis B (CHB) and acute-on-chronic liver failure caused by HBV (HBVACLF). The results revealed that the samples contained unique and distinct types of RNAs in exosomes. ${ }^{225}$ Zika virus (ZIKV) infection causes severe neurological malfunctions including microcephaly in neonates and other complications associated with Guillain-Barré syndrome in adults. Interestingly, ZIKV uses exosomes as mediators of viral transmission between neurons and increases production of exosomes from neuronal cells. Exosomes derived from ZIKV-infected cells contained both ZIKV viral RNA and protein(s) which are highly infectious to naïve cells. ZIKV uses neutral Sphingomyelinase (nSMase)-2/SMPD3 to regulate production and release of exosomes. $^{226}$

During infections, viruses replicate in host cells through vesicular trafficking through a sequence of complexes known as ESCRT, and assimilate viral constituents into exosomes. Exosomes encapsulate viral antigens to maximize infectivity by hiding viral genomes, entrapping the immune system, and maximizing viral infection in uncontaminated cells. Exosomes can be used as a source of viral antigens that can be targeted for therapeutic use. A Variety of infectious diseases caused by viruses such as HCV, ZIKV, West Nile virus (WNV), and DENV enter into the host cells using clathrin-mediated or receptor-mediated endocytosis. For example, HCV infects host cells by specific targeting of cells through cellular contact, and hepatocyte-derived exosomes that contain $\mathrm{HCV}$ RNA can stimulate innate immune cells. ${ }^{217,227-230}$ Exosomes show structural and molecular similarity to HIV-1 and HIV-2, which are enclosed by a lipid bilayer, and in the vital features of size and density, RNA species, and macro biomolecules including carbohydrates, lipids, and proteins. HIV-infected cells release enriched viral RNAs containing exosomes derived from $\mathrm{HIV}$-infected cells and are enhanced with viral RNAs and Nef protein. ${ }^{6,38,231-236}$ Izquierdo-Useros et al reported that both exosomes and HIV-1 express sialyllactose-containing gangliosides and interact with each other via sialic-acid-binding immunoglobulin-like lectins (Siglecs)-1. Siglecs-1 stimulates mature dendritic cell $(\mathrm{mDC})$ capture and storage of both exosomes and HIV-1 in mDCs. ${ }^{237}$ Exosomes released from HIV-infected T cells contain transactivation response (TAR) element RNA, which stimulate proliferation, migration, and invasion of oral/oropharyngeal and lung cancer cells. ${ }^{238}$ Nuclear VP40 from Ebola virus VP40 upregulates cyclin D1 levels, resulting in dysregulated cell cycle and EV biogenesis. Synthesized extracellular vesicles contain cytokines and EBOV proteins from infected cells, which are responsible for the destruction of immune cells during EBOV pathogenesis. ${ }^{239}$ HIV enters into the host cells 
through human T-cell immunoglobin mucin (TIM) proteins. TIMs are a group of proteins (TIM-1, TIM-3, and TIM-4) that promote phagocytosis of apoptotic cells. ${ }^{240}$ TIM-4 is involved in HIV-1 exosome-dependent cellular entry mechanisms. Substantiating this hypothesis, neural stem cell (NSC)-derived exosomes containing TIM-4 protein increase HIV-1 exosome-dependent cellular entry into host cells, and antibody against TIM4 inhibits exosomemediated entry of HIV in various types of cell. ${ }^{241}$

\section{Exosomes as Diagnostic Markers}

Exosomes show immense promise in biomedical applications due to their potential in drug delivery, the carriage of biomolecular markers of many diseases, and cellular protection. In addition, they can be used in non-invasive diagnostics or minimum invasive diagnostics. ${ }^{150}$ Detection of biomarkers is vital for early diagnosis of cancer and also critical for treatment. Several studies have documented the importance of exosomes in a variety of diseases, although further examination of the biology and functions of exosomes is warranted due to the continuing emergence of new diseases in the present world. The complex cargo of exosomes facilitates the exploration of a variety of diagnostic windows into disease detection, monitoring, and treatment. Exosomes are found in all biological fluids and are secreted by all cells, rendering them attractive for use through minimally invasive liquid biopsies, and they have the potential for use in longitudinal sampling to follow disease progression. ${ }^{242}$ Exosomes are produced and secreted by almost all body fluids, including blood, urine, saliva, breast milk, cerebrospinal fluid, semen, amniotic fluid, and ascites. These exosomes contain micro RNAs, proteins, and lipids serving as diagnostic markers. ${ }^{120}$ Exosomes are used in diagnostic applications in various kinds of diseases, such as cardiovascular diseases (CVDs), ${ }^{243}$ diseases of the central nervous system (CNS), ${ }^{244}$ cancer, ${ }^{245}$ and other prominent diseases including in the liver, ${ }^{246}$ kidney, ${ }^{247}$ and lung. ${ }^{248}$ Exosomes are potentially used to detect cancer-associated mutations in serum and also for the transfer of genomic DNA from donor cells to recipient cells. ${ }^{249}$ Exosomes carrying specific miRNAs or groups of miRNAs can be used as diagnostic markers to detect cancer. For example, exosomes containing oncogenic Kras, which have tumorsuppressor miRNAs-100, seem to have high diagnostic value, which could facilitate the differentiation of the expression pattern between cancer cells and normal cells. $^{250,251}$ Similarly, miR-21 is considered to be diagnostic marker for various types of cancer including glioblastomas and pancreatic, colorectal, colon, liver, breast, ovarian, and esophageal cancers. ${ }^{252}$ Tumor suppressor miRNAs, such as miR-146a and miR-34a, function as diagnostic tools to detect liver, breast, colon, pancreatic, and hematologic malignancies. ${ }^{251}$ Exosomes containing GPC1 (glypican 1) are used as diagnostic markers to detect pancreatic, breast, and colon cancer. ${ }^{253,254}$

Exosomes play critical roles in various types of disease, and particularly in cancer progression and resistance to therapy. The unique biogenesis of exosomes and their biological features have generated excitement for their potential use as biomarkers for cancer. ${ }^{255}$ Generally, exosomes are produced and secreted by most cells and contain all the biological components of a cell. Hence, exosomes are found in all biological fluids and provide excellent opportunities for use as biomarkers. ${ }^{242}$ Surface proteins of exosomes are involved in the regulation of the tumor immune microenvironment and the monitoring of immunotherapies. Hence, exosome proteins play a critical role in cancer signaling. ${ }^{256}$ Exosomes from patients with metastatic pancreatic cancer show a higher mutant Kras allele frequency than exosomes from patients with local disease. In addition, the exosomes also accumulate a significantly higher level of cancer cell-specific DNA such as cytoplasmic DNA. ${ }^{8,257}$ Exosomes protect DNA and RNA from enzymatic degradation by encapsulation and stability in exosomes. The enhanced stability and retention of exosomes in liquid biopsies increases the availability and performance of exosomes as cancer biomarkers. ${ }^{258}$ Cancer cells contain cargo molecules, such as nucleic acid, proteins, metabolites, and lipids that are relatively different from normal cells, which is a contributing factor for their candidacy as cancer biomarkers. Exosomes isolated and purified from patient plasma samples enriched for miR-10b-5p, miR-101-3p, and miR-143-5p have been identified as potential diagnostic markers for gastric cancer with lymph node metastasis, gastric cancer with ovarian metastasis, and gastric cancer with liver metastasis, respectively. ${ }^{259}$ Kato et al analyzed the expression of CD44 protein and mRNA from cell lysates and exosomes from prostate cancer cells. ${ }^{260}$ Exosomes from serum containing CD44v8-10 mRNA was used as a diagnostic marker for docetaxel resistance in prostate cancer patients. The study was performed to evaluate plasma exosomal mRNA-125a-5p and miR-141-5p miRNAs as biomarkers for the diagnosis of prostate cancer from 19 healthy individuals and 31 prostate cancer patients. In comparing the miR-125a-5p/miR-141-5p level ratio, 
prostate cancer patients had significantly higher levels of miR-125a-5p/miR-141-5p. The findings from this study demonstrated that plasma exosomal expression of miR141-3p and miR-125a-5p are markers of specific tumor traits associated with prostate cancer. ${ }^{261}$ Serum samples from 81 patients with gastric cancer showed that exosomes contained significant levels of long non-coding RNA (lncRNA) H19, which could be a diagnostic marker for gastric cancer. ${ }^{262}$ Plasma exosomes are suitable candidates as biomarkers for various diseases. For instance, plasma exosome lncRNA expression profiles were examined in esophageal squamous cell carcinoma (ESCC) patients. The findings suggest that five different types of lncRNAs were at significantly higher levels in exosomes from ESCC patients than in non-cancer controls. These lncRNAs may serve as highly effective, noninvasive biomarkers for ESCC diagnosis. $^{263}$ Differential expression of lncRNAs, such as LINC00462, HOTAIR, and MALAT1, are significantly upregulated in hepatocellular carcinoma (HCC) tissues. The exosomes of the control group had a larger number of lncRNAs with a high amount of alternative splicing compared to hepatic disease patients. ${ }^{264}$ To demonstrate exosomes as a non-invasive cancer diagnostic tool, RNAsequencing analysis was performed between three pairs of non-small-cell lung cancer (NSCLC) patients and controls from Chinese populations. The results show that circ_0047921, circ_0056285, and circ_0007761 were significantly expressed and that these exosomal circRNAs are promising biomarkers for NSCLC diagnosis. ${ }^{265}$ Exosomes were isolated from the serum of 34 patients with acute myocardial infarction (AMI), 31 patients with unstable angina (UA), and 22 healthy controls. The isolated exosomes exhibited higher levels of miR-126 and miR-21 in the patients with UA and AMI than in the healthy controls. $^{266} \mathrm{Xu}$ et al designed a study to examine tumorderived exosomes as diagnostic biomarkers. In this study exosome miRNA microarray analysis was performed in the peripheral blood from four lung adenocarcinoma patients, including two with metastasis and two without metastasis. The results found that miR-4436a and miR-4687-5p were upregulated in the metastasis and non-metastasis group, while miR-22-3p, miR-3666, miR-4448, miR-4449, miR6751-5p, and miR-92a-3p were downregulated. Exosomes containing miR-4448 have served as a diagnostic marker of patients with adenocarcinoma metastasis. Increased understanding of exosome biogenesis, structure, and function would enhance the performance of biomarkers in various kinds of disease diagnosis, prognosis, and surveillance. ${ }^{267}$

\section{Therapeutic Potential and Clinical Implications of Exosomes}

Exosomes have unique features such as ease of handling, molecular composition, and critical immunogenicity, and it is particularly easy to use them to transfer genes and proteins into cells. These unique characteristic features can inhibit angiogenesis and cancer metastasis, which are the two main targets of cancer therapy. ${ }^{268,269}$ Exosomes have potential therapeutic applications in a variety of diseases due to their potential capacity as vehicles for the delivery of therapeutic agents (Figure 5). Exosomes from colon cancer cells contain the highly immunogenic antigens MelanA/Mart-1 and gp100, serving as an indicator of tumor origin in particular organelles. Animal studies have demonstrated that tumor-derived antigen-containing exosomes induce potent antitumor T-cell responses and tumor regression. ${ }^{270}$ Exosomes containing tumor antigens are able to stimulate CD4+and CD8+T cells, and antigenpresenting exosomes inhibit tumor growth. ${ }^{135,271,272}$ MSCderived exosomes exhibit the immunomodulatory and cytoprotective activities of their parent cells. ${ }^{273,274}$ Similarly, exosomes derived from bone marrow show protective roles in myocardial ischemia/reperfusion injury, ${ }^{109}$ hypoxia-induced pulmonary hypertension, ${ }^{275}$ and brain injury, ${ }^{276,277}$ and inhibit breast cancer growth via vascular endothelial growth factor down-regulation and miR-16 transfer in mice. ${ }^{278}$ Mesenchymal cell- and epithelial cellderived exosomes exhibit tolerance and without any undesired side effects in patients and also act as therapeutic agents themselves. ${ }^{48,279}$ Exosomes engineered with ligands containing RGD peptide are used to induce signaling in specific cell types, and doxorubicin-loaded exosomes derived from dendritic cells show therapeutic responses in mammary tumor-bearing mice. ${ }^{46}$ Exosomal microRNAs are able to control other cells, and the delivery of miRNA or siRNA payload promotes anticancer activity in mammary carcinoma and glioma. ${ }^{280,281}$ Rabies virus glycoprotein (RVG)-modified dendritic cell-derived exosomes suppress the expression of BACE1 in the brain, which indicates the therapeutic potential of exosomes to target AD. ${ }^{282}$ Furthermore, these exosomes stimulated neurite outgrowth in cultured astrocytes by transferring miR-133b between cells. ${ }^{27}$ Immunotherapy is able to induce tumor-targeting immunity or an antitumor host 


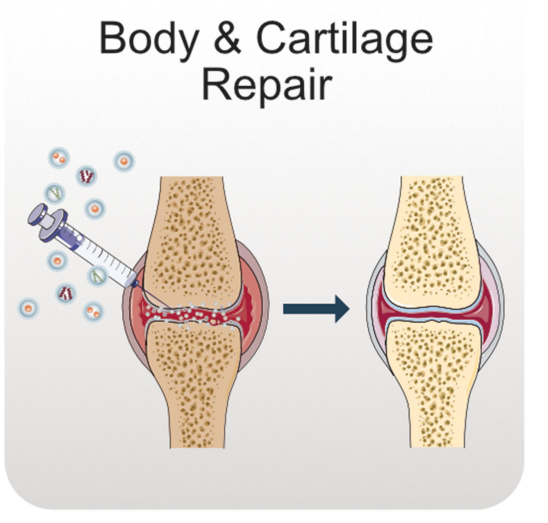

\section{Heart \& Myocardial Functions}

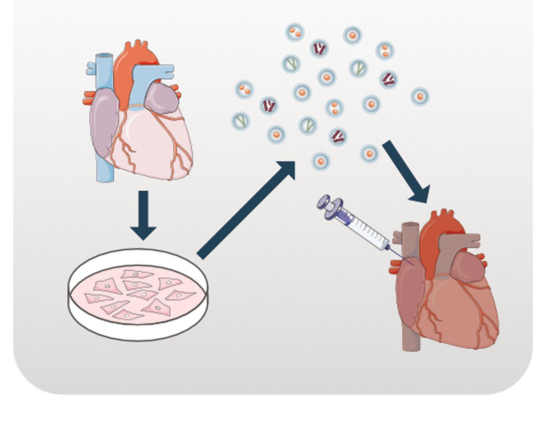

Soft Tissue Repair

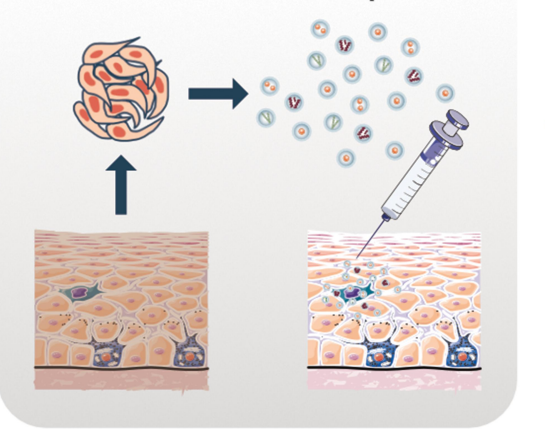

\section{Therapeutic Potential of Exosomes}

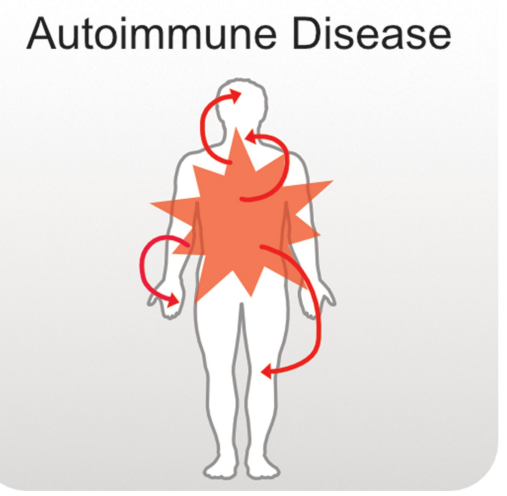

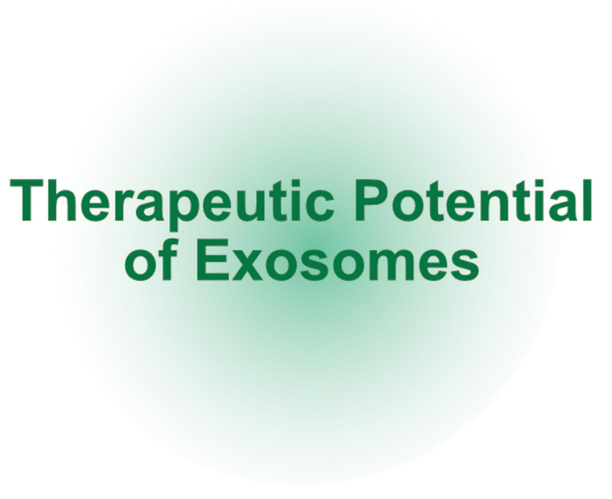

Infectious Diseases

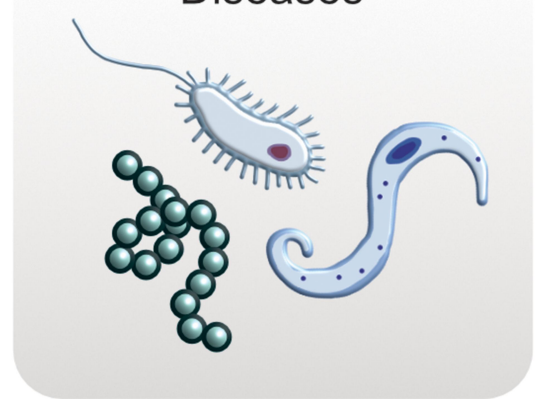

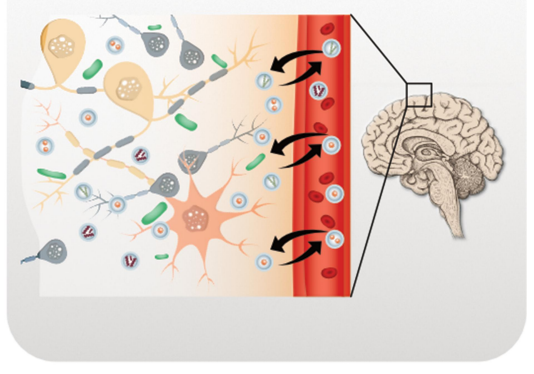

\section{Brain/Neural Tissue Injuries}

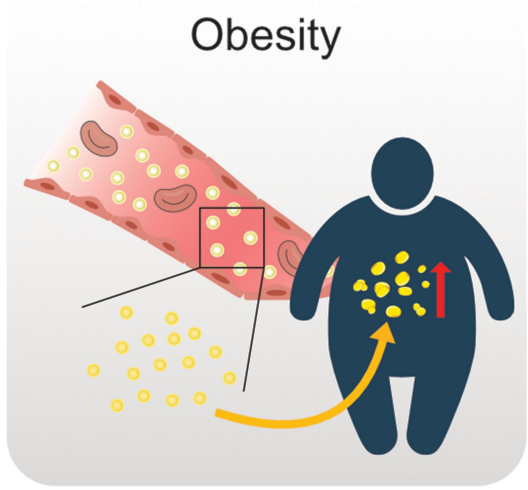

\section{Lung \& Liver Diseases}

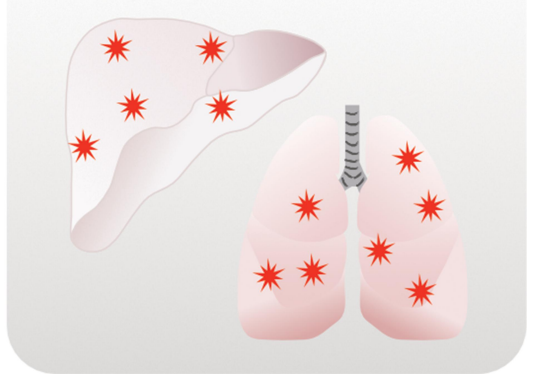

Figure 5 Therapeutic potential and versatile clinical implications of exosomes.

immune response. For example, tumor-associated antigenloaded mature autologous dendritic cells increase survival of metastatic castration-resistant patients. $^{283}$ Exosome therapy induces upregulation of CD122 molecules in CD4+ $\mathrm{T}$ cells, whereas the lymphocyte pool is stable. Multiple vaccinations with exosomes increase circulating CD3-/CD56+ natural killer (NK) cells. ${ }^{284}$ An in vitro study demonstrated that adipose stem cell-derived exosomes up-regulate the peroxisome proliferator-activated receptor gamma coactivator 1 , phosphorylate the cyclic AMP response element binding protein, and ameliorate abnormal apoptotic protein levels. ${ }^{285}$ Exosomes are used as potential carriers to carry anti-inflammatory drugs. Curcumin-encapsulated exosomes show significant antiinflammatory activity, and exosomes are also used to deliver anti-inflammatory drugs to the brain through a noninvasive intranasal route. ${ }^{286,287}$ Turturici et al reported that specific progenitor cell-derived EVs contain biological cargo that promotes angiogenesis and tissue repair, and modulates immune functions. ${ }^{288}$

Generally, exosomes serve as vehicles for the delivery of drugs and are also actively involved as therapeutic agents. Conversely, injected exosomes enter into other cells and deliver functional cargo molecules very 
efficiently and rapidly, with minimal immune clearance and are well tolerated. ${ }^{16,21,245,289,290}$ Intravenous administration of human MSC-derived exosomes supports neuroprotection in a swine model of traumatic brain injury. ${ }^{291} \mathrm{In}$ vitro and in vivo models demonstrate that exosomes from human-induced pluripotent stem cell-derived mesenchymal stromal Cells (hiPSC-MSCs) protect the liver against hepatic ischemia/reperfusion injury through increasing the level of proliferation of primary hepatocytes, activity of sphingosine kinase, and synthesis of sphingosine-1-phosphate (S1P). ${ }^{292}$ Exosomes derived from macrophages show potential for use in neurological diseases because of their easy entry into the brain by crossing the bloodbrain barrier (BBB). Catalase-loaded exosomes displayed a neuroprotective effect in a mouse model of PD and exosomes loaded with dopamine entered into the brain better in comparison to free dopamine. ${ }^{33,293}$ Treatment of tumor-bearing mice with autologous exosomes loaded with gemcitabine significantly suppressed tumor growth and increase longevity, and caused only minimal damage to normal tissues. The study demonstrated that autologous exosomes are safe and effective vehicles for targeted delivery of GEM against pancreatic cancer. ${ }^{294}$

\section{Exosomes as Drug Delivery Vehicles}

Generally, lipid-based nanoparticles such as liposomes or micelles, or synthetic delivery systems have been adopted to transport active molecules. However, the merits of synthetic systems are limited due to various factors including inefficiency, cytotoxicity and/or immunogenicity. Therefore, the development of natural carrier systems is indispensable. One of the most prominent examples of such natural carriers are exosomes, which are used to transport drug and active biomolecules. Exosomes are more compatible with other cells because they carry various targeting molecules from their cells of origin. Exosomes are nano-sized membrane vesicles derived from almost all cell types, which carry a variety of cargo molecules from their parent cells to other cells. Due to their natural biogenesis and unique qualities, including high biocompatibility, enhanced stability, and limited immunogenicity, they have advantages as drug delivery systems (DDSs) compared to traditional synthetic delivery vehicles. For instance, extracellular vesicles, including exosomes, carry and protect a wide array of nucleic acids and can potentially deliver these into recipient cells. ${ }^{6}$ EVs possess inherent targeting properties due to their lipid composition and protein content enabling them to cross biological barriers, and these salient features exploit endogenous intracellular trafficking mechanisms and trigger a response upon uptake by recipient cells. ${ }^{45,295-297}$ The lipid composition and protein content of exocytic vesicles have specific tropism to specific organs. ${ }^{296}$ The integrin of exosomes determines the ability to alter the pharmacokinetics of EVs and increase their accumulation in various type of organs including brain, lungs, or liver. ${ }^{117}$ For example, EVs containing Tspan8 in complex with integrin alpha4 were shown to be preferentially taken up by pancreatic cells. ${ }^{298}$ Similarly, the lipid composition of EVs influences the cellular uptake of EVs by macrophages. ${ }^{299}$ EVs derived from dendritic cell achieved targeted knockdown by fusion between expression of Lamp $2 b$ and neuron-specific RVG peptide by using siRNA in neuronal cell. ${ }^{45}$ EVs loaded with Cre recombinase protein were able to deliver functional CreFRB to recipient cells through active and passive mechanisms in the presence of endosomal escape, enhancing the compounds chloroquine and UNC10217832A. ${ }^{300} \mathrm{EVs}$ from cardiosphere-derived cells achieved targeted delivery by fusion of the N-terminus of Lamp2b to a cardiomyocytespecific peptide (CMP). ${ }^{301}$ RVG-exosomes were used to deliver anti-alpha-synuclein shRNA minicircle (shRNA$\mathrm{MC)}$ therapy to the alpha-synuclein preformed-fibrilinduced mouse model of parkinsonism. This therapy decreased alpha-synuclein aggregation, reduced the loss of dopaminergic neurons, and improved clinical symptoms. RVG exosome-mediated therapy prolonged the effectiveness and was specifically delivered into the brain. ${ }^{302}$ Zhang et al evaluated the effects of umbilical cord-derived macrophage exosomes loaded with cisplatin on the growth and drug resistance of ovarian cancer cells. High loading efficiency of cisplatin was achieved by membrane disruption of exosomes by sonication. ${ }^{303}$ Incorporation of cisplatin into umbilical cord blood-derived M1 macrophage exosomes increased cytotoxicity 3.3-fold in drug-resistant A2780/ DDP cells and 1.4-fold in drug-sensitive A2780 cells, compared to chemotherapy alone. Loading of cisplatin into M2 exosomes increased cytotoxicity by nearly 1.7 -fold in drugresistant A2780/DDP cells and 1.4-fold in drug-sensitive A2780 cells. The findings suggest that cisplatin-loaded M1 exosomes are potentially powerful tools for the delivery of chemotherapeutics to treat cancers regardless of drug resistance. Shandilya et al developed a chemical-free and nonmechanical method for the encapsulation and intercellular delivery of siRNA using milk-derived exosomes through conjugation between bovine lactoferrin with poly-L-lysine, wherein lactoferrin as a ligand was captured by the GAPDH 
present in exosomes, loading siRNA in an effortless manner. ${ }^{304}$ Targeted drug delivery was achieved with low immunogenicity and toxicity using exosomes derived from immature dendritic cells (imDCs) from BALB/c mice by expressing the fusion protein RGD. Recombinant methioninase (rMETase) was loaded into tumor-targeting iRGDExos. The findings suggest that the iRGD-Exos-rMETase group exhibited significant antitumor activity compared to the rMETase group. ${ }^{305}$ Several diseases show high inflammatory responses; therefore, amelioration of inflammatory responses is a critical factor. The inflammatory responses in various disease models can be attenuated through introduction of super-repressor IKB ( $\operatorname{srI\kappa B}$ ), which is the dominant active form of $I \kappa B \alpha$, and can inhibit translocation of nuclear factor $\mathrm{\kappa B}$ into the nucleus. Intraperitoneal injection of purified srIкB-loaded exosomes (Exo-srIkBs) showed diminished mortality and systemic inflammation in septic mouse models. ${ }^{306}$ Systemic administration of macrophage-derived exosomes modified with azide and conjugated with dibenzocyclooctyne-modified antibodies of CD47 and SIRP $\alpha$ (aCD47 and aSIRP $\alpha$ ) through $\mathrm{pH}$-sensitive linkers can actively and specifically target tumors through distinguishing between aCD47 and CD47 on the tumor cell surface. ${ }^{307}$ SPION-decorated exosomes prepared using fusion proteins of cell-penetrating peptides (CPP) and TNF- $\alpha$ (CTNF- $\alpha$ )anchored exosomes coupled with superparamagnetic iron oxide nanoparticles (CTNF- $\alpha$-exosome-SPIONs) significantly enhanced tumor cell growth inhibition via induction of the TNFR I-mediated apoptotic pathway. Furthermore, in vivo studies in murine melanoma subcutaneous cancer models showed that TNF- $\alpha$-loaded exosome-based vehicle delivery enhanced cancer targeting under an external magnetic field and suppressed tumor growth with mitigating toxicity. ${ }^{308} \mathrm{Yu}$ et al ${ }^{309}$ developed a formulation of erastinloaded exosomes labeled with folate (FA) to form FAvectorized exosomes loaded with erastin (erastin@FAexo) to target triple-negative breast cancer (TNBC) cells with overexpression of FA receptors. Erastin@FA-exo increased the uptake efficiency of erastin and also significantly inhibited the proliferation and migration of MDAMB-231 cells compared with erastin@exo and free erastin. Interestingly, erastin@FA-exo promoted ferroptosis with intracellular depletion of glutathione and ROS generation. Plasma exosomes (Exo) loaded with quercetin (Exo-Que) improved the drug bioavailability, enhanced the brain targeting of Que and potently ameliorated cognitive dysfunction in okadaic acid (OA)-induced $\mathrm{AD}$ mice compared to free quercetin by inhibiting phosphorylated tau-mediated neurofibrillary tangles. ${ }^{310}$ Spinal cord injury (SCI) causes paralysis of the limbs. To determine the role of resveratrol in SCI, exosomes derived from resveratrol-treated primary microglia were used as carriers which are able to enhance the solubility of resveratrol and enhance penetration of the drug through the BBB, thereby increasing its concentration in the CNS. The findings demonstrated that Exo + Res are highly effective at crossing the BBB with good stability, suggesting they have potential for enhancing targeted drug delivery and recovering neuronal function in SCI therapy, and is likely associated with the induction of autophagy and inhibition of apoptosis via the PI3K signaling pathway. ${ }^{311}$ Delivery of miR-204-5p by exosomes inhibits cancer cell proliferation and tumor growth, and induces apoptosis and chemoresistance by specifically suppressing the target genes of miR-204-5p in human cancer cells. ${ }^{312}$ Engineered exosomes with RVG peptide on the surface for neuron targeting and NGF-loaded exosomes $\left(\mathrm{NGF} @ \mathrm{Exo}^{\mathrm{RVG}}\right.$ ) were efficiently delivered into ischemic cortex, with a burst release of encapsulated NGF protein and de novo NGF protein translated from the delivered mRNA. The delivered NGF protein showed high stability and a long retention time, and also reduced inflammation by reshaping microglia polarization, promoted cell survival, and increased the population of double cortin-positive cells, a neuroblast marker. ${ }^{313}$ Intranasal delivery of mesenchymal stem cell-derived extracellular vesicles exerts immunomodulatory and neuroprotective effects in a $3 \times \mathrm{Tg}$ model of AD by activation of microglia cells and increased dendritic spine density. ${ }^{314}$ Exosome-encapsulated paclitaxel showed efficacy in the treatment of multi-drug resistant cancer cells and it overcomes MDR in cancer cells. ${ }^{315,316}$ Saari et al found that the loading of Paclitaxel to autologous prostate cancer cell-derived EVs increased its cytotoxic effect. ${ }^{316}$ Exosome loaded doxorubicin (exoDOX) avoids undesired and unnecessary heart toxicity by partially limiting the crossing of DOX through the myocardial endothelial cells. ${ }^{317}$ Studies from in vitro and in vivo demonstrate that exosome loaded doxorubicin showed that exosomes did not decrease the efficacy of DOX and there is no cardiotoxicity in DOX-treated mice. ${ }^{318}$

\section{Outstanding Developments in Exosome Biology}

The intrinsic properties of exosomes have been exploited to control various types of diseases, including neurodegenerative conditions and cancer, through promoting or restraining the 
delivery of proteins, metabolites, and nucleic acids into recipient cells effectively, eventually altering their biological response. Furthermore, exosomes can be engineered to deliver diverse therapeutic payloads to the target site, including siRNAs, antisense oligonucleotides, chemotherapeutic agents, and immune modulators. The natural lipid and protein composition of exosomes increases bioavailability and minimizes undesirable side effects to the recipients. Due to the availability of exosomes in biological fluid, they can be easily used as potential biomarkers for diagnosis of diseases. Exosomes are naturally decorated with numerous ligands on the surface that can be beneficial for preferential tumor targeting. ${ }^{282}$ Due to their unique properties, including superior targeting capabilities and safety profile, exosomes are the subject of clinical trials as cancer therapeutic agents. ${ }^{284}$ Exosomes derived from DCs loaded with tumor antigens have been used to vaccinate cancer patients with the goal of enhancing anti-tumor immune responses. $^{284,319,320}$

\section{Challenges in Exosome Biology}

Due to the potential level of various types of cargoes and salient features, exosomes are involved in intercellular messaging and disease diagnosis. As a result of dedicated studies, exosomes have been identified as natural drug delivery vehicles. However, we still face challenges regarding the purity of exosomes due to the lack of standardized techniques for their isolation and purification, inefficient separation methods, difficulties in characterization, and lack of specific biomarkers. ${ }^{321}$ The first challenge is the use of conventional methods, which are laborious for isolation and purification, time consuming, and vulnerable to contamination by other impurities, which will affect drug delivery processes. The second challenge is the various cellular origins of exosomes, which could affect specific applications. For example, in the application of exosomes in cancer therapy, we should avoid the use of exosomes derived from cancer cells, due to their oncogenic properties. Finally, exosomes have variable properties due to extraction from different types of cell and different cell culture techniques. Therefore, there is a necessity to address and overcome the challenges. There is also a need for an exosome consortium to develop common protocols for the development of rapid and precise methods of exosome isolation, and to assist the selection of sources that are dependent upon the specific therapeutic application. The most important challenge of exosome biology is the clinical translation of exosomebased research using different cell sources. Further characterization studies based on therapeutic applications are needed. Finally, important steps need to be taken to purify exosomes in a feasible, rapid, cost-effective, and scalable manner, which are free from downstream processing and have minimal processing times, that are specifically targeted to therapeutic applications and clinical settings.

\section{Exosomes and Clinical Trials}

The achievement of exosome therapy is based on success rate of clinical trials. Exosomes with size ranges from 60 to 200-nm have been used as an active pharmaceutical ingredient or drug carrier in disease treatment. Exosomes derived from human and plant-derived exosomes are registered in clinical trials, but more complete reports are available for human-derived exosomes. ${ }^{322}$ There are two major exosomes from DCs and MSCs are frequently used in clinical trials, which potentially induce inflammation response and inflammation treatment. The more crucial aspect of exosomes in clinical trials needs to comply with good manufacturing practice (GMP) including upstream, downstream and quality control. Recently, France and USA conducted clinical trials using EVs containing MHC-peptide complexes derived from dendritic could alter tumor growth in immune competent mice and a Phase I anti-non-small cell lung cancer ${ }^{319,320}$ and several other clinical trial studies are shown in Table 1. Recent clinical case shows promising results with MSC-EVs derived from unrelated bone marrow donors for the treatment of a steroidrefractory graft-vs-host disease patient. ${ }^{279}$ Similarly, exosomes were used for the treatment of various types of diseases such as melanoma, non-small-cell-lung cancer, colon cancer and chronic kidney disease. ${ }^{284,319,320,323,324}$

\section{Conclusions and Future Perspectives}

Exosomes are nano-sized membrane vesicles released by the fusion of an organelle of the endocytic pathway, a multivesicular body, with the plasma membrane. Since the last decade, exosomes have played a critical role in nanomedicine and studies related to exosome biology have increased immensely. Exosomes are secreted by almost all cell types and they are found in almost all types of body fluids. They function as mediators of cell-cell communications and play a significant role in both physiological and pathological processes. Exosomes carry a wide range of cargoes including proteins, lipids, RNAs, and DNA, which mediate signaling to recipient cells or tissues, making them 
Table I Summary of the Exosome Used in Clinical Trials (Source: clinicaltrials.com)

\begin{tabular}{|c|c|c|c|c|c|}
\hline S. No. & Type of Disease & $\begin{array}{l}\text { Year/Phase/ } \\
\text { No. of } \\
\text { Patients }\end{array}$ & Dose & Type of Administration & Results \\
\hline 1 & Melanoma & $\begin{array}{ll}\text { - } & 2000 \\
\text { - } & \text { Phase I } \\
\text { - } & \mathrm{n}=15\end{array}$ & $\begin{array}{l}4 \times 10^{13} \text { or } \\
1.3 \times 10^{13} \mathrm{MHC} \\
\text { Class II } \\
\text { Molecules }\end{array}$ & $\begin{array}{l}\text { SC ( } 90 \% \text { of the volume) and } \\
\text { ID }(10 \%) \text { injections weekly } \\
\text { for } 4 \text { weeks }\end{array}$ & $\begin{array}{l}\text { No Grade II toxicity; No detected MAGE3-specific } \\
\text { CD4+ and CD8+ T cells }\end{array}$ \\
\hline 2 & Non-small cell lung cancer & $\begin{array}{ll}\text { - } & \text { Not } \\
\text { - } & \text { reported } \\
\text { - } & \text { Phase I } \\
\mathrm{n}=4\end{array}$ & $\begin{array}{l}1.3 \times 10^{13} \mathrm{MHC} \\
\text { Class II } \\
\text { Molecules }\end{array}$ & $\begin{array}{l}\text { SC }(90 \% \text { of the volume) and } \\
\text { ID }(10 \%) \text { injections weekly } \\
\text { for } 4 \text { weeks }\end{array}$ & $\begin{array}{l}\text { Well-tolerated and only Grade } 1-2 \text { adverse events; } \\
\text { MAGE-specific T-cell responses in I/3 patients; } \\
\text { increased NK lytic activity in } 2 / 4 \text { patients }\end{array}$ \\
\hline 3 & Non-small cell lung cancer & $\begin{array}{l}\text { - } \text { May } 2010 \\
\text { - } \\
\text { - } \mathrm{n}=22\end{array}$ & $\begin{array}{l}8.5 \times 10^{11}-1.0 \\
\times 10^{13} \mathrm{MHC} \\
\text { Class II } \\
\text { Molecules }\end{array}$ & Four ID at I-week Intervals & $\begin{array}{l}\text { One patient had Grade } 3 \text { hepatotoxicity; boosting the } \\
\text { NK cell arm of antitumor immunity }\end{array}$ \\
\hline 4 & Colon cancer & $\begin{array}{ll}\text { - } & \text { Not } \\
\text { - } & \text { reported, } \\
\text { - } & \text { Phase I } \\
\end{array}$ & $\begin{array}{l}100-500 \mu g \text { of } \\
\text { protein }\end{array}$ & Four SC at weekly Intervals & $\begin{array}{l}\text { Safe, well-tolerated; tumor-specific antitumor CTL } \\
\text { response in exosome plus GM-CSF group }\end{array}$ \\
\hline 5 & Chronic kidney diseases & 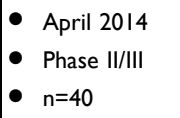 & $100 \mu g / k g /$ dose & $\begin{array}{l}\text { Two doses of MSC-EVs, } \\
\text { Intra-arterial and intravenous } \\
\text { injections }\end{array}$ & $\begin{array}{l}\text { Safe, well-tolerated; improved kidney function; } \\
\text { decreased inflammation }\end{array}$ \\
\hline 6 & $\begin{array}{l}\text { Colon cancer } \\
\text { (NCT01294072) }\end{array}$ & $\begin{array}{l}\text { - January 2011 } \\
\text { - Phase I } \\
\text { - } \mathrm{n}=35\end{array}$ & Not reported & Tablets taken daily for 7 days & Active, not recruiting \\
\hline 7 & $\begin{array}{l}\text { Radiation- and } \\
\text { chemotherapy-induced } \\
\text { Oral mucositis } \\
\text { (NCT01668849) }\end{array}$ & $\begin{array}{ll}\text { - } & \text { August } 2012 \\
\text { - } & \text { Phase I } \\
\text { - } & \mathrm{n}=60\end{array}$ & Not reported & $\begin{array}{l}\text { Oral administration daily for } \\
35 \text { days }\end{array}$ & Active, not recruiting \\
\hline 8 & $\begin{array}{l}\text { Malignant ascites and } \\
\text { pleural effusion } \\
\text { (NCT0I854866) }\end{array}$ & $\begin{array}{l}\text { - } \text { May } 2013 \\
\text { - } \text { Phase II } \\
\text { - } \mathrm{n}=30\end{array}$ & Not reported & $\begin{array}{l}\text { Perfused to the pleural or } \\
\text { peritoneal cavity, } 4 \text { times/ } \\
\text { week }\end{array}$ & Unknown status \\
\hline 9 & $\begin{array}{l}\text { Type I diabetes } \\
\text { (NCT0213833I) }\end{array}$ & $\begin{array}{l}\text { - } \\
\text { - } \\
\text { - Phase I } \\
\text { - } \mathrm{n}=20\end{array}$ & $\begin{array}{l}(1.22-1.51) \times 10^{6} \\
\text { cells/kg, Day } 0 \\
\text { and } 7\end{array}$ & Intravenous & Unknown status \\
\hline 10 & $\begin{array}{l}\text { Malignant pleural effusion } \\
\text { (NCT02657460) }\end{array}$ & $\begin{array}{l}\text { - January } 2016 \\
\text { - } \text { Phase II } \\
\text { - } \mathrm{n}=90\end{array}$ & Not reported & Not reported & Recruiting \\
\hline 11 & $\begin{array}{l}\text { Macular holes } \\
\text { (NCT03437759) }\end{array}$ & $\begin{array}{l}\text { - } \text { March } 2017 \\
\text { - } \text { Phase I } \\
\text { - } \mathrm{n}=44\end{array}$ & 50 or $20 \mu g$ & Dripped into vitreous cavity & Recruiting \\
\hline 12 & $\begin{array}{l}\text { Bronchopulmonary } \\
\text { dysplasia (NCT0385784I) }\end{array}$ & $\begin{array}{ll}\text { - } & \text { June } 2019 \\
\text { - } & \text { Phase I } \\
\text { - } & \mathrm{n}=18\end{array}$ & $\begin{array}{l}200 \text { pmol } \\
\text { phospholipid/Kg }\end{array}$ & Intravenous & Recruiting \\
\hline 13 & $\begin{array}{l}\text { Acute ischemic stroke } \\
\text { (NCT03384433) }\end{array}$ & $\begin{array}{ll}\text { - } & \text { April } 2019 \\
\text { - } & \text { Phase } 1 / 11 \\
\text { - } & n=5\end{array}$ & $200 \mu \mathrm{g}$ & Stereotaxic injection & Not yet recruiting \\
\hline 14 & $\begin{array}{l}\text { Metastatic pancreatic } \\
\text { cancer (NCT0360863I) }\end{array}$ & $\begin{array}{l}\text { - } \text { March } 2020 \\
\text { - } \text { Phase I } \\
\text { - } \mathrm{n}=28\end{array}$ & Not reported & $\begin{array}{l}\text { IV on days I, } 4 \text {, and } 10 . \\
\text { Treatment repeated every } 14 \\
\text { days for up to } 3 \text { courses }\end{array}$ & Not yet recruiting \\
\hline
\end{tabular}


a promising diagnostic biomarker and therapeutic tool for the treatment of cancers and other pathologies. In this review, we summarized what is known to date about the factors involved in exosome biogenesis and the role of exosomes in intercellular signaling and cell-cell communications, immune responses, cellular homeostasis, autophagy, and infectious diseases. Further, we reviewed the role of exosomes as diagnostic markers, and their therapeutic and clinical implications. Furthermore, we highlighted the challenges and outstanding developments in exosome research. The clinical application of exosomes is inevitable and they represent multicomponent biomarkers for several diseases including cancer and neurological diseases, etc. Recently, the mortality rate due to various types of cancers has increased. Therefore, therapies are essential to reduce mortality rates. At this juncture, we need sensitive, rapid, cost-effective, and largescale production of exosomes to use as cancer biomarkers in diagnosis, prognosis, and surveillance. Furthermore, novel technologies are required for further tailoring exosomes as drug delivery vesicles with high drug pay loads, high specificity and low immunogenicity, and free of toxicity undesired side-effects. In addition, standardized and uniform protocols are necessary to isolate and purify exosomes for clinical applications, and more precise isolation and characterization procedures are required to increase understanding of the heterogeneity of exosomes, their cargo, and functions. There is an urgent need for information regarding the composition and mechanisms of action of the various substances in exosomes and to determine how to obtain highly purified exosomes at the right dosage for their clinical use. Currently, exosomes represent a promising tool in the field of nanomedicine and may provide solutions to a variety of today's medical mysteries.

The future direction of exosome research must focus on addressing the differential responses of communication between normal cells and cancer cells, how normal cells rapidly become cancerous, and how exosomes plays critical role in cancer progression via cell-cell communications. In vivo studies need to urgently address the critical factors such as biogenesis, trafficking, and cellular entry of exosomes originating from unmanipulated exosomes that control regulatory pathological functions. Further studies are required to decipher the mechanism of the cell-specific secretion and transport of exosomes, and the biological controls exerted by target cells. Exosomes represent a clinically significant nanoplatform. To substantiate this idea, numerous systematic in vivo studies are necessary to demonstrate the potency and toxicology of exosomes, which could help bring this novel idea a step closer to clinical reality. The most vital part of the system is to optimize the conditions for the engineering of exosomes that are nontoxic, for use in clinical trials. Furthermore, the translation of exosomes into clinical therapies requires their categorization as active drug components or drug delivery vehicles. Finally, future research should focus on the nanoengineering of exosomes that are tailored specifically for drug delivery and clinical efficacy.

\section{Acknowledgments}

Although we are the authors of this review, we would never have been able to complete it without the great many people who have contributed to the field of exosomes biogenesis, functions, therapeutic and clinical implications of exosomes aspects. We owe our gratitude to all those researchers who have made this review possible. We have cited as many references as permitted and apologize to the authors of those publications that we have not cited due to the limitation of references. We apologize to other authors who have worked on these aspects but whom we have unintentionally overlooked.

This study was supported by the KU-Research Professor Program of Konkuk University.

\section{Funding}

This work was supported by a grant from the Science Research Center (2015R1A5A1009701) of the National Research Foundation of Korea.

\section{Disclosure}

The authors report no conflicts of interest related to this work..

\section{References}

1. Raposo G, Stoorvogel W. Extracellular vesicles: exosomes, microvesicles, and friends. J Cell Biol. 2013;200(4):373-383. doi:10.1083/ jcb.201211138

2. Denzer K, Kleijmeer MJ, Heijnen HF, Stoorvogel W, Geuze HJ. Exosome: from internal vesicle of the multivesicular body to intercellular signaling device. J Cell Sci. 2000;113(Pt 19):3365-3374.

3. Yáñez-Mó M, Siljander PR, Andreu Z, et al. Biological properties of extracellular vesicles and their physiological functions. $J$ Extracell Vesicles. 2015;4:27066. doi:10.3402/jev.v4.27066

4. Cocucci E, Meldolesi J. Ectosomes and exosomes: shedding the confusion between extracellular vesicles. Trends Cell Biol. 2015;25 (6):364-372. doi:10.1016/j.tcb.2015.01.004

5. Yamamoto T, Kosaka N, Ochiya T. Latest advances in extracellular vesicles: from bench to bedside. Sci Technol Adv Mater. 2019;20 (1):746-757. doi:10.1080/14686996.2019.1629835

6. Valadi H, Ekström K, Bossios A, Sjöstrand M, Lee JJ, Lötvall JO. Exosome-mediated transfer of mRNAs and microRNAs is a novel mechanism of genetic exchange between cells. Nat Cell Biol. 2007;9 (6):654-659. doi:10.1038/ncb1596 
7. Kosaka N, Ochiya T. Unraveling the mystery of cancer by secretory microRNA: horizontal microRNA transfer between living cells. Front Genet. 2011;2:97. doi:10.3389/fgene.2011.00097

8. Takahashi A, Okada R, Nagao K, et al. Exosomes maintain cellular homeostasis by excreting harmful DNA from cells. Nat Commun. 2017;8:15287. doi:10.1038/ncomms15287

9. Gruenberg J, van der Goot FG. Mechanisms of pathogen entry through the endosomal compartments. Nat Rev Mol Cell Biol. 2006;7(7):495-504. doi:10.1038/nrm1959

10. Zhang J, Li S, Li L, et al. Exosome and exosomal microRNA: trafficking, sorting, and function. Genomics Proteomics Bioinformatics. 2015;13(1):17-24. doi:10.1016/j.gpb.2015.02.001

11. Pegtel DM, Gould SJ. Exosomes. Annu Rev Biochem. 2019;88:487-514. doi:10.1146/annurev-biochem-013118-111902

12. Maia J, Caja S, Strano Moraes MC, Couto N, Costa-Silva B. Exosome-based cell-cell communication in the tumor microenvironment. Front Cell Dev Biol. 2018;6:18. doi:10.3389/ fcell.2018.00018

13. Zhang Q, Higginbotham JN, Jeppesen DK, et al. Transfer of functional cargo in exomeres. Cell Rep. 2019;27(3):940-954. e946. doi:10.1016/j.celrep.2019.01.009

14. Hessvik NP, Llorente A. Current knowledge on exosome biogenesis and release. Cell Mol Life Sci. 2018;75(2):193-208. doi:10.1007/s00018-017-2595-9

15. Palanisamy V, Sharma S, Deshpande A, Zhou H, Gimzewski J, Wong DT. Nanostructural and transcriptomic analyses of human saliva derived exosomes. PLoS One. 2010;5(1):e8577. doi:10.1371/journal.pone.0008577

16. Kalluri R. The biology and function of exosomes in cancer. $J$ Clin Invest. 2016;126(4):1208-1215. doi:10.1172/jci81135

17. Théry C, Zitvogel L, Amigorena S. Exosomes: composition, biogenesis and function. Nat Rev Immunol. 2002;2(8):569-579. doi: $10.1038 /$ nri855

18. Théry C, Ostrowski M, Segura E. Membrane vesicles as conveyors of immune responses. Nat Rev Immunol. 2009;9 (8):581-593. doi:10.1038/nri2567

19. Janowska-Wieczorek A, Wysoczynski M, Kijowski J, et al. Microvesicles derived from activated platelets induce metastasis and angiogenesis in lung cancer. Int $J$ Cancer. 2005;113 (5):752-760. doi:10.1002/ijc. 20657

20. Lakkaraju A, Rodriguez-Boulan E. Itinerant exosomes: emerging roles in cell and tissue polarity. Trends Cell Biol. 2008;18 (5):199-209. doi:10.1016/j.tcb.2008.03.002

21. Ferguson SW, Nguyen J. Exosomes as therapeutics: the implications of molecular composition and exosomal heterogeneity $J$ Control Release. 2016;228:179-190. doi:10.1016/j. jconrel.2016.02.037

22. Soung YH, Ford S, Zhang V, Chung J. Exosomes in cancer diagnostics. Cancers (Basel). 2017;9(12):8. doi:10.3390/ cancers 9010008

23. Meehan K, Vella LJ. The contribution of tumour-derived exosomes to the hallmarks of cancer. Crit Rev Clin Lab Sci. 2016;53 (2):121-131. doi:10.3109/10408363.2015.1092496

24. Quah BJ, O'Neill HC. Maturation of function in dendritic cells for tolerance and immunity. J Cell Mol Med. 2005;9(3):643-654. doi:10.1111/j.1582-4934.2005.tb00494.x

25. Bell BM, Kirk ID, Hiltbrunner S, Gabrielsson S, Bultema JJ. Designer exosomes as next-generation cancer immunotherapy Nanomedicine. $\quad 2016 ; 12(1): 163-169 . \quad$ doi:10.1016/j.nano.201 5.09.011

26. Pegtel DM, Peferoen L, Amor S. Extracellular vesicles as modulators of cell-to-cell communication in the healthy and diseased brain. Philos Trans $R$ Soc Lond B Biol Sci. 2014;369 (1652):20130516. doi:10.1098/rstb.2013.0516
27. Xin $\mathrm{H}$, Li Y, Buller B, et al. Exosome-mediated transfer of miR-133b from multipotent mesenchymal stromal cells to neural cells contributes to neurite outgrowth. Stem Cells. 2012;30 (7):1556-1564. doi:10.1002/stem.1129

28. Rajendran L, Honsho M, Zahn TR, et al. Alzheimer's disease beta-amyloid peptides are released in association with exosomes. Proc Natl Acad Sci U S A. 2006;103(30):11172-11177. doi:10.1073/pnas.0603838103

29. Guo BB, Bellingham SA, Hill AF. The neutral sphingomyelinase pathway regulates packaging of the prion protein into exosomes. J Biol Chem. 2015;290(6):3455-3467. doi:10.1074/jbc.M114.605253

30. Simons M, Raposo G. Exosomes-vesicular carriers for intercellular communication. Curr Opin Cell Biol. 2009;21(4):575-581. doi:10.1016/j.ceb.2009.03.007

31. Natasha G, Gundogan B, Tan A, et al. Exosomes as immunotheranostic nanoparticles. Clin Ther. 2014;36(6):820-829. doi:10.1016/j.clinthera.2014.04.019

32. Pascucci L, Coccè V, Bonomi A, et al. Paclitaxel is incorporated by mesenchymal stromal cells and released in exosomes that inhibit in vitro tumor growth: a new approach for drug delivery. $J$ Control Release. 2014;192:262-270. doi:10.1016/j.jconrel.2014.07.042

33. Haney MJ, Klyachko NL, Zhao Y, et al. Exosomes as drug delivery vehicles for Parkinson's disease therapy. J Control Release. 2015;207:18-30. doi:10.1016/j.jconrel.2015.03.033

34. Kalani A, Tyagi A, Tyagi N. Exosomes: mediators of neurodegeneration, neuroprotection and therapeutics. Mol Neurobiol. 2014;49(1):590-600. doi:10.1007/s12035-013-8544-1

35. Minciacchi VR, Freeman MR, Di Vizio D. Extracellular vesicles in cancer: exosomes, microvesicles and the emerging role of large oncosomes. Semin Cell Dev Biol. 2015;40:41-51. doi:10.1016/j. semcdb.2015.02.010

36. Colombo M, Moita C, van Niel G, et al. Analysis of ESCRT functions in exosome biogenesis, composition and secretion highlights the heterogeneity of extracellular vesicles. J Cell Sci. 2013;126(Pt 24):5553-5565. doi:10.1242/jcs. 128868

37. Ghossoub R, Lembo F, Rubio A, et al. Syntenin-ALIX exosome biogenesis and budding into multivesicular bodies are controlled by ARF6 and PLD2. Nat Commun. 2014;5:3477. doi:10.1038/ ncomms 4477

38. Kowal J, Tkach M, Théry C. Biogenesis and secretion of exosomes. Curr Opin Cell Biol. 2014;29:116-125. doi:10.1016/ j.ceb.2014.05.004

39. Villarroya-Beltri C, Baixauli F, Gutiérrez-Vázquez C, SánchezMadrid F, Mittelbrunn M. Sorting it out: regulation of exosome loading. Semin Cancer Biol. 2014;28:3-13. doi:10.1016/j. semcancer.2014.04.009

40. Fader CM, Sánchez DG, Mestre MB, Colombo MI. TI-VAMP /VAMP7 and VAMP3/cellubrevin: two v-SNARE proteins involved in specific steps of the autophagy/multivesicular body pathways. Biochim Biophys Acta. 2009;1793(12):1901-1916. doi:10.1016/j.bbamcr.2009.09.011

41. Ostrowski M, Carmo NB, Krumeich S, et al. Rab27a and Rab27b control different steps of the exosome secretion pathway. Nat Cell Biol. 2010;12(1):19-30; sup pp 11-13. doi:10.1038/ncb2000

42. Gross JC, Chaudhary V, Bartscherer K, Boutros M. Active Wnt proteins are secreted on exosomes. Nat Cell Biol. 2012;14 (10):1036-1045. doi:10.1038/ncb2574

43. Hyenne V, Apaydin A, Rodriguez D, et al. RAL-1 controls multivesicular body biogenesis and exosome secretion. J Cell Biol. 2015;211(1):27-37. doi:10.1083/jcb.201504136

44. Gudbergsson JM, Johnsen KB, Skov MN, Duroux M. Systematic review of factors influencing extracellular vesicle yield from cell cultures. Cytotechnology. 2016;68(4):579-592. doi:10.1007/ s10616-015-9913-6 
45. Alvarez-Erviti L, Seow Y, Schapira AH, et al. Lysosomal dysfunction increases exosome-mediated alpha-synuclein release and transmission. Neurobiol Dis. 2011;42(3):360-367. doi:10.1016/j. nbd.2011.01.029

46. Tian Y, Li S, Song J, et al. A doxorubicin delivery platform using engineered natural membrane vesicle exosomes for targeted tumor therapy. Biomaterials. 2014;35(7):2383-2390. doi:10.1016/j.biomaterials.2013.11.083

47. Chen TS, Arslan F, Yin Y, et al. Enabling a robust scalable manufacturing process for therapeutic exosomes through oncogenic immortalization of human ESC-derived MSCs. $J$ Transl Med. 2011;9:47. doi:10.1186/1479-5876-9-47

48. Yeo RW, Lai RC, Zhang B, et al. Mesenchymal stem cell: an efficient mass producer of exosomes for drug delivery. Adv Drug Deliv Rev. 2013;65(3):336-341. doi:10.1016/j.addr.2012.07.001

49. Zheng Y, Campbell EC, Lucocq J, Riches A, Powis SJ. Monitoring the Rab27 associated exosome pathway using nanoparticle tracking analysis. Exp Cell Res. 2013;319 (12):1706-1713. doi:10.1016/j.yexcr.2012.10.006

50. Wang JS, Wang FB, Zhang QG, Shen ZZ, Shao ZM. Enhanced expression of Rab27A gene by breast cancer cells promoting invasiveness and the metastasis potential by secretion of insulin-like growth factor-II. Mol Cancer Res. 2008;6 (3):372-382. doi:10.1158/1541-7786.Mcr-07-0162

51. Dong B, Lv G, Wang Q, et al. Targeting A20 enhances TRAIL-induced apoptosis in hepatocellular carcinoma cells. Biochem Biophys Res Commun. 2012;418(2):433-438. doi:10.1016/j.bbrc.2012.01.056

52. Wu X, Hu A, Zhang M, Chen Z. Effects of Rab27a on proliferation, invasion, and anti-apoptosis in human glioma cell. Tumour Biol. 2013;34(4):2195-2203. doi:10.1007/s13277-013-0756-5

53. Wang Q, Ni Q, Wang X, Zhu H, Wang Z, Huang J. High expression of RAB27A and TP53 in pancreatic cancer predicts poor survival. Med Oncol. 2015;32(1):372. doi:10.1007/s12032-0140372-2

54. McAndrews KM, Kalluri R. Mechanisms associated with biogenesis of exosomes in cancer. Mol Cancer. 2019;18(1):52. doi:10.1186/s12943-019-0963-9

55. Hoshino D, Kirkbride KC, Costello K, et al. Exosome secretion is enhanced by invadopodia and drives invasive behavior. Cell Rep. 2013;5(5):1159-1168. doi:10.1016/j.celrep.2013.10.050

56. Casado S, Lobo M, Paíno CL. Dynamics of plasma membrane surface related to the release of extracellular vesicles by mesenchymal stem cells in culture. Sci Rep. 2017;7(1):6767. doi:10.1038/ s41598-017-07265-x

57. Cantaluppi V, Gatti S, Medica D, et al. Microvesicles derived from endothelial progenitor cells protect the kidney from ischemia-reperfusion injury by microRNA-dependent reprogramming of resident renal cells. Kidney Int. 2012;82(4):412-427. doi:10.1038/ki.2012.105

58. Shen B, Fang Y, Wu N, Gould SJ. Biogenesis of the posterior pole is mediated by the exosome/microvesicle protein-sorting pathway. J Biol Chem. 2011;286(51):44162-44176. doi:10.1074/ jbc.M111.274803

59. Shao H, Chung J, Balaj L, et al. Protein typing of circulating microvesicles allows real-time monitoring of glioblastoma therapy. Nat Med. 2012;18(12):1835-1840. doi:10.1038/nm.2994

60. Welsch S, Keppler OT, Habermann A, Allespach I, KrijnseLocker J, Kräusslich HG. HIV-1 buds predominantly at the plasma membrane of primary human macrophages. PLoS Pathog. 2007;3(3):e36. doi:10.1371/journal.ppat.0030036

61. Deneka M, Pelchen-Matthews A, Byland R, Ruiz-Mateos E, Marsh M. In macrophages, HIV-1 assembles into an intracellular plasma membrane domain containing the tetraspanins CD81, CD9, and CD53. J Cell Biol. 2007;177(2):329-341. doi: $10.1083 /$ jcb. 200609050
62. Nkwe DO, Pelchen-Matthews A, Burden JJ, Collinson LM, Marsh M. The intracellular plasma membrane-connected compartment in the assembly of HIV-1 in human macrophages. BMC Biol. 2016;14:50. doi:10.1186/s12915-016-0272-3

63. Fordjour FK, Daaboul GG, Gould SJ. A shared pathway of exosome biogenesis operates at plasma and endosome membranes. bioRxiv. 2019;545228. doi:10.1101/545228

64. Baietti MF, Zhang Z, Mortier E, et al. Syndecan-syntenin-ALIX regulates the biogenesis of exosomes. Nat Cell Biol. 2012;14 (7):677-685. doi:10.1038/ncb2502

65. Liang Y, Eng WS, Colquhoun DR, Dinglasan RR, Graham DR, Mahal LK. Complex N-linked glycans serve as a determinant for exosome/microvesicle cargo recruitment. J Biol Chem. 2014;289 (47):32526-32537. doi:10.1074/jbc.M114.606269

66. Fang Y, Wu N, Gan X, Yan W, Morrell JC, Gould SJ. Higherorder oligomerization targets plasma membrane proteins and HIV gag to exosomes. PLoS Biol. 2007;5(6):e158. doi:10.1371/journal.pbio. 0050158

67. Snead WT, Hayden CC, Gadok AK, et al. Membrane fission by protein crowding. Proc Natl Acad Sci U S A. 2017;114(16): E3258-E3267. doi:10.1073/pnas.1616199114

68. Llorente A, Skotland T, Sylvänne T, et al. Molecular lipidomics of exosomes released by PC-3 prostate cancer cells. Biochim Biophys Acta. 2013;1831(7):1302-1309. doi:10.1016/j. bbalip.2013.04.011

69. Skotland T, Sandvig K, Llorente A. Lipids in exosomes: current knowledge and the way forward. Prog Lipid Res. 2017;66:30-41. doi:10.1016/j.plipres.2017.03.001

70. Egea-Jimenez AL, Zimmermann P. Phospholipase D and phosphatidic acid in the biogenesis and cargo loading of extracellular vesicles. J Lipid Res. 2018;59(9):1554-1560. doi:10.1194/jlr.R083964

71. Trajkovic K, Hsu C, Chiantia S, et al. Ceramide triggers budding of exosome vesicles into multivesicular endosomes. Science. 2008;319(5867):1244-1247. doi:10.1126/science.1153124

72. Stenmark H. Rab GTPases as coordinators of vesicle traffic. Nat Rev Mol Cell Biol. 2009;10:513-525. doi:10.1038/nrm2728

73. Gerber PP, Cabrini M, Jancic C, et al. Rab27a controls HIV-1 assembly by regulating plasma membrane levels of phosphatidylinositol 4,5-bisphosphate. J Cell Biol. 2015;209(3):435-452. doi:10.1083/jcb.201409082

74. Blanc L, Vidal M. New insights into the function of Rab GTPases in the context of exosomal secretion. Small GTPases. 2018;9(1-2):95-106. doi:10.1080/21541248.2016.1264352

75. Hsu C, Morohashi Y, Yoshimura S, et al. Regulation of exosome secretion by Rab35 and its GTPase-activating proteins TBC1D10A-C. J Cell Biol. 2010;189(2):223-232. doi:10.1083/ jcb.200911018

76. Gurunathan S, David D, Gerst JE. Dynamin and clathrin are required for the biogenesis of a distinct class of secretory vesicles in yeast. EMBO J. 2002;21(4):602-614. doi:10.1093/emboj/21.4.602

77. Henne WM, Buchkovich NJ, Emr SD. The ESCRT pathway. Dev Cell. 2011;21(1):77-91. doi:10.1016/j.devcel.2011.05.015

78. Guo H, Chitiprolu M, Roncevic L, et al. Atg5 disassociates the V (1) $\mathrm{V}(0)$-ATPase to promote exosome production and tumor metastasis independent of canonical macroautophagy. Dev Cell. 2017;43(6):716-730.e717. doi:10.1016/j.devcel.2017.11.018

79. Abdulrahman BA, Abdelaziz DH, Schatzl HM. Autophagy regulates exosomal release of prions in neuronal cells. $J$ Biol Chem. 2018;293(23):8956-8968. doi:10.1074/jbc.RA117.000713

80. Hendrix A, Hume AN. Exosome signaling in mammary gland development and cancer. Int J Dev Biol. 2011;55(7-9):879-887. doi:10.1387/ijdb.113391ah

81. Galindo-Hernandez O, Villegas-Comonfort S, Candanedo F, et al. Elevated concentration of microvesicles isolated from peripheral blood in breast cancer patients. Arch Med Res. 2013;44 (3):208-214. doi:10.1016/j.arcmed.2013.03.002 
82. Kavanagh EL, Lindsay S, Halasz M, et al. Protein and chemotherapy profiling of extracellular vesicles harvested from therapeutic induced senescent triple negative breast cancer cells. Oncogenesis. 2017;6(10):e388. doi:10.1038/oncsis.2017.82

83. Kosgodage US, Mould R, Henley AB, et al. Cannabidiol (CBD) is a novel inhibitor for exosome and microvesicle (EMV) release in cancer. Front Pharmacol. 2018;9:889. doi:10.3389/fphar.2018.00889

84. Im EJ, Lee CH, Moon PG, et al. Sulfisoxazole inhibits the secretion of small extracellular vesicles by targeting the endothelin receptor A. Nat Commun. 2019;10(1):1387. doi:10.1038/s41467019-09387-4

85. Choi DS, Yang JS, Choi EJ, et al. The protein interaction network of extracellular vesicles derived from human colorectal cancer cells. J Proteome Res. 2012;11(2):1144-1151. doi:10.1021/pr200842h

86. Brandi J, Pozza ED, Dando L, et al. Secretome protein signature of human pancreatic cancer stem-like cells. $J$ Proteomics. 2016;136:1-12. doi:10.1016/j.jprot.2016.01.017

87. Escola JM, Kleijmeer MJ, Stoorvogel W, Griffith JM, Yoshie O, Geuze HJ. Selective enrichment of tetraspan proteins on the internal vesicles of multivesicular endosomes and on exosomes secreted by human B-lymphocytes. J Biol Chem. 1998;273 (32):20121-20127. doi:10.1074/jbc.273.32.20121

88. Gal D, MacDonald PC, Porter JC, Smith JW, Simpson ER. Effect of cell density and confluency on cholesterol metabolism in cancer cells in monolayer culture. Cancer Res. 1981;41 (2):473-477.

89. Steinman RA, Wentzel A, Lu Y, Stehle C, Grandis JR. Activation of Stat 3 by cell confluence reveals negative regulation of Stat 3 by cdk2. Oncogene. 2003;22(23):3608-3615. doi:10.1038/sj. onc. 1206523

90. Hayes O, Ramos B, Rodríguez LL, Aguilar A, Badía T, Castro FO. Cell confluency is as efficient as serum starvation for inducing arrest in the G0/G1 phase of the cell cycle in granulosa and fibroblast cells of cattle. Anim Reprod Sci. 2005;87(3-4):181-192. doi:10.1016/j.anireprosci.2004.11.011

91. Savina A, Furlán M, Vidal M, Colombo MI. Exosome release is regulated by a calcium-dependent mechanism in K562 cells. J Biol Chem. 2003;278(22):20083-20090. doi:10.1074/jbc. M301642200

92. Svensson KJ, Kucharzewska P, Christianson HC, et al. Hypoxia triggers a proangiogenic pathway involving cancer cell microvesicles and PAR-2-mediated heparin-binding EGF signaling in endothelial cells. Proc Natl Acad Sci U S A. 2011;108 (32):13147-13152. doi:10.1073/pnas.1104261108

93. King HW, Michael MZ, Gleadle JM. Hypoxic enhancement of exosome release by breast cancer cells. BMC Cancer. 2012;12:421. doi:10.1186/1471-2407-12-421

94. Kucharzewska P, Christianson HC, Welch JE, et al. Exosomes reflect the hypoxic status of glioma cells and mediate hypoxia-dependent activation of vascular cells during tumor development. Proc Natl Acad Sci $U$ S A. 2013;110 (18):7312-7317. doi:10.1073/pnas.1220998110

95. Koumangoye RB, Sakwe AM, Goodwin JS, Patel T, Ochieng J. Detachment of breast tumor cells induces rapid secretion of exosomes which subsequently mediate cellular adhesion and spreading. PLoS One. 2011;6(9):e24234. doi:10.1371/journal. pone. 0024234

96. Théry C, Regnault A, Garin J, et al. Molecular characterization of dendritic cell-derived exosomes. Selective accumulation of the heat shock protein hsc73. J Cell Biol. 1999;147(3):599-610. doi:10.1083/jcb.147.3.599

97. Bryan N, Andrews KD, Loughran MJ, Rhodes NP, Hunt JA. Elucidating the contribution of the elemental composition of fetal calf serum to antigenic expression of primary human umbilical-vein endothelial cells in vitro. Biosci Rep. 2011;31 (3):199-210. doi:10.1042/bsr20100064
98. Lund P, Pilgaard L, Duroux M, Fink T, Zachar V. Effect of growth media and serum replacements on the proliferation and differentiation of adipose-derived stem cells. Cytotherapy. 2009;11 (2):189-197. doi:10.1080/14653240902736266

99. de Jong OG, Verhaar MC, Chen Y, et al. Cellular stress conditions are reflected in the protein and RNA content of endothelial cell-derived exosomes. J Extracell Vesicles. 2012;1(1):18396. doi:10.3402/jev.v1i0.18396

100. Shelke GV, Lässer C, Gho YS, Lötvall J. Importance of exosome depletion protocols to eliminate functional and RNA-containing extracellular vesicles from fetal bovine serum. $J$ Extracell Vesicles. 2014;3(1):24783. doi:10.3402/jev.v3.24783

101. Pirkmajer S, Chibalin AV. Serum starvation: caveat emptor. Am J Physiol Cell Physiol. 2011;301(2):C272-C279. doi:10.1152/ ajpcell.00091.2011

102. Lee HD, Kim YH, Kim DS. Exosomes derived from human macrophages suppress endothelial cell migration by controlling integrin trafficking. Eur J Immunol. 2014;44(4):1156-1169. doi:10.1002/eji.201343660

103. Yang Q, Nanayakkara GK, Drummer C, et al. Low-intensity ultrasound-induced anti-inflammatory effects are mediated by several new mechanisms including gene induction, immunosuppressor cell promotion, and enhancement of exosome biogenesis and docking. Front Physiol. 2017;8:818. doi:10.3389/ fphys.2017.00818

104. Datta A, Kim H, Lal M, et al. Manumycin A suppresses exosome biogenesis and secretion via targeted inhibition of Ras/Raf/ERK1/2 signaling and hnRNP H1 in castration-resistant prostate cancer cells. Cancer Lett. 2017;408:73-81. doi:10.1016/j.canlet.2017.08.020

105. Palazzolo S, Memeo L, Hadla M, et al. Cancer extracellular vesicles: next-generation diagnostic and drug delivery nanotools. Cancers (Basel). 2020;12(11):3165. doi:10.3390/cancers12113165

106. Rieu S, Géminard C, Rabesandratana H, Sainte-Marie J, Vidal M. Exosomes released during reticulocyte maturation bind to fibronectin via integrin alpha4beta1. Eur J Biochem. 2000;267 (2):583-590. doi:10.1046/j.1432-1327.2000.01036.x

107. Boriachek K, Islam MN, Möller A, et al. Biological functions and current advances in isolation and detection strategies for exosome nanovesicles. Small. 2018;14(6). doi:10.1002/smll.201702153

108. Février B, Raposo G. Exosomes: endosomal-derived vesicles shipping extracellular messages. Curr Opin Cell Biol. 2004;16 (4):415-421. doi:10.1016/j.ceb.2004.06.003

109. Lai RC, Arslan F, Lee MM, et al. Exosome secreted by MSC reduces myocardial ischemia/reperfusion injury. Stem Cell Res. 2010;4(3):214-222. doi:10.1016/j.scr.2009.12.003

110. Lobb RJ, van Amerongen R, Wiegmans A, Ham S, Larsen JE, Möller A. Exosomes derived from mesenchymal non-small cell lung cancer cells promote chemoresistance. Int $J$ Cancer. 2017;141(3):614-620. doi:10.1002/ijc.30752

111. Latifkar A, Ling L, Hingorani A, et al. Loss of Sirtuin 1 alters the secretome of breast cancer cells by impairing lysosomal integrity. Dev Cell. 2019;49(3):393-408.e397. doi:10.1016/j.devcel.201 9.03.011

112. Peinado H, Zhang H, Matei IR, et al. Pre-metastatic niches: organ-specific homes for metastases. Nat Rev Cancer. 2017;17 (5):302-317. doi:10.1038/nrc.2017.6

113. Dai X, Chen C, Yang Q, et al. Exosomal circRNA 100284 from arsenite-transformed cells, via microRNA-217 regulation of $\mathrm{EZH} 2$, is involved in the malignant transformation of human hepatic cells by accelerating the cell cycle and promoting cell proliferation. Cell Death Dis. 2018;9(5):454. doi:10.1038/s41419018-0485-1

114. Camussi G, Deregibus MC, Bruno S, Cantaluppi V, Biancone L. Exosomes/microvesicles as a mechanism of cell-to-cell communication. Kidney Int. 2010;78(9):838-848. doi:10.1038/ ki.2010.278 
115. Nazimek K, Bryniarski K, Santocki M, Ptak W. Exosomes as mediators of intercellular communication: clinical implications. Pol Arch Med Wewn. 2015;125(5):370-380. doi:10.20452/pamw.2840

116. Costa-Silva B, Aiello NM, Ocean AJ, et al. Pancreatic cancer exosomes initiate pre-metastatic niche formation in the liver. Nat Cell Biol. 2015;17(6):816-826. doi:10.1038/ncb3169

117. Hoshino A, Costa-Silva B, Shen TL, et al. Tumour exosome integrins determine organotropic metastasis. Nature. 2015;527 (7578):329-335. doi:10.1038/nature 15756

118. Tkach M, Théry C. Communication by extracellular vesicles: where we are and where we need to go. Cell. 2016;164 (6):1226-1232. doi:10.1016/j.cell.2016.01.043

119. Khalyfa A, Poroyko VA, Qiao Z, et al. Exosomes and metabolic function in mice exposed to alternating dark-light cycles mimicking night shift work schedules. Front Physiol. 2017;8:882. doi:10.3389/fphys.2017.00882

120. Zhang Y, Liu Y, Liu H, Tang WH. Exosomes: biogenesis, biologic function and clinical potential. Cell Biosci. 2019;9:19. doi:10.1186/s13578-019-0282-2

121. Liu X, Li Q, Niu X, et al. Exosomes secreted from human-induced pluripotent stem cell-derived mesenchymal stem cells prevent osteonecrosis of the femoral head by promoting angiogenesis. Int J Biol Sci. 2017;13(2):232-244. doi:10.7150/ijbs.16951

122. Liu X, Wang L, Ma C, Wang G, Zhang Y, Sun S. Exosomes derived from platelet-rich plasma present a novel potential in alleviating knee osteoarthritis by promoting proliferation and inhibiting apoptosis of chondrocyte via Wnt/ $\beta$-catenin signaling pathway. J Orthop Surg Res. 2019;14(1):470. doi:10.1186/s13018-019-1529-7

123. Zhupanyn $\mathrm{P}$, Ewe A, Büch $\mathrm{T}$, et al. Extracellular vesicle (ECV)-modified polyethylenimine (PEI) complexes for enhanced siRNA delivery in vitro and in vivo. $J$ Control Release. 2020;319:63-76. doi:10.1016/j.jconrel.2019.12.032

124. Sun Z, Wang L, Zhou Y, et al. Glioblastoma stem cell-derived exosomes enhance stemness and tumorigenicity of glioma cells by transferring Notch1 protein. Cell Mol Neurobiol. 2020;40 (5):767-784. doi:10.1007/s10571-019-00771-8

125. Wang B, Mao JH, Wang BY, et al. Exosomal miR-1910-3p promotes proliferation, metastasis, and autophagy of breast cancer cells by targeting MTMR3 and activating the NF- $\mathrm{KB}$ signaling pathway. Cancer Lett. 2020;489:87-99. doi:10.1016/j. canlet.2020.05.038

126. Hyung S, Jeong J, Shin K, et al. Exosomes derived from chemically induced human hepatic progenitors inhibit oxidative stress induced cell death. Biotechnol Bioeng. 2020;117(9):2658-2667. doi:10.1002/bit.27447

127. Norouzi-Barough L, Asgari Khosro Shahi A, Mohebzadeh F, Masoumi L, Haddadi MR, Shirian S. Early diagnosis of breast and ovarian cancers by body fluids circulating tumor-derived exosomes. Cancer Cell Int. 2020;20:187. doi:10.1186/s12935-020-01276-x

128. He C, Hua W, Liu J, Fan L, Wang H, Sun G. Exosomes derived from endoplasmic reticulum-stressed liver cancer cells enhance the expression of cytokines in macrophages via the STAT3 signaling pathway. Oncol Lett. 2020;20(1):589-600. doi:10.3892/ ol.2020.11609

129. Wei H, Xu Y, Chen Q, Chen H, Zhu X, Li Y. Mesenchymal stem cell-derived exosomal miR-223 regulates neuronal cell apoptosis. Cell Death Dis. 2020;11(4):290. doi:10.1038/s41419-020-2490-4

130. Fan B, Li C, Szalad A, et al. Mesenchymal stromal cell-derived exosomes ameliorate peripheral neuropathy in a mouse model of diabetes. Diabetologia. 2020;63(2):431-443. doi:10.1007/ s00125-019-05043-0

131. Long X, Yao X, Jiang Q, et al. Astrocyte-derived exosomes enriched with miR-873a-5p inhibit neuroinflammation via microglia phenotype modulation after traumatic brain injury. J Neuroinflammation. 2020;17(1):89. doi:10.1186/s12974-02001761-0
132. Lin Y, Zhang C, Xiang P, Shen J, Sun W, Yu H. Exosomes derived from HeLa cells break down vascular integrity by triggering endoplasmic reticulum stress in endothelial cells. $J$ Extracell Vesicles. 2020;9(1):1722385. doi:10.1080/20013078.202 0.1722385

133. Mendt M, Kamerkar S, Sugimoto H, et al. Generation and testing of clinical-grade exosomes for pancreatic cancer. JCI Insight. 2018;3(8). doi:10.1172/jci.insight.99263

134. Raposo G, Nijman HW, Stoorvogel W, et al. B lymphocytes secrete antigen-presenting vesicles. $J$ Exp Med. 1996;183 (3):1161-1172. doi:10.1084/jem.183.3.1161

135. Zitvogel L, Regnault A, Lozier A, et al. Eradication of established murine tumors using a novel cell-free vaccine: dendritic cell-derived exosomes. Nat Med. 1998;4(5):594-600. doi:10.1038/nm0598-594

136. Montecalvo A, Shufesky WJ, Stolz DB, et al. Exosomes as a short-range mechanism to spread alloantigen between dendritic cells during $\mathrm{T}$ cell allorecognition. J Immunol. 2008;180 (5):3081-3090. doi:10.4049/jimmunol.180.5.3081

137. Giri PK, Schorey JS. Exosomes derived from M. Bovis BCG infected macrophages activate antigen-specific CD4+ and CD8+ T cells in vitro and in vivo. PLoS One. 2008;3(6):e2461. doi:10.1371/journal.pone.0002461

138. Montecalvo A, Larregina AT, Shufesky WJ, et al. Mechanism of transfer of functional microRNAs between mouse dendritic cells via exosomes. Blood. 2012;119(3):756-766. doi:10.1182/blood2011-02-338004

139. Ding G, Zhou L, Shen T, Cao L. IFN- $\gamma$ induces the upregulation of RFXAP via inhibition of miR-212-3p in pancreatic cancer cells: a novel mechanism for IFN- $\gamma$ response. Oncol Lett. 2018;15(3):3760-3765. doi:10.3892/ol.2018.7777

140. Ying $\mathrm{X}, \mathrm{Wu} \mathrm{Q}, \mathrm{Wu} \mathrm{X}$, et al. Epithelial ovarian cancer-secreted exosomal miR-222-3p induces polarization of tumor-associated macrophages. Oncotarget. 2016;7(28):43076-43087. doi:10.18 632/oncotarget.9246

141. Kitai Y, Kawasaki T, Sueyoshi T, et al. DNA-containing exosomes derived from cancer cells treated with topotecan activate a STING-dependent pathway and reinforce antitumor immunity. J Immunol. 2017;198(4):1649-1659. doi:10.4049/jimmunol.16 01694

142. Torralba D, Baixauli F, Villarroya-Beltri C, et al. Priming of dendritic cells by DNA-containing extracellular vesicles from activated T cells through antigen-driven contacts. Nat Commun. 2018;9(1):2658. doi:10.1038/s41467-018-05077-9

143. Montermini L, Meehan B, Garnier D, et al. Inhibition of oncogenic epidermal growth factor receptor kinase triggers release of exosome-like extracellular vesicles and impacts their phosphoprotein and DNA content. J Biol Chem. 2015;290(40):24534-24546. doi:10.1074/jbc.M115.679217

144. Chennakrishnaiah S, Meehan B, D'Asti E, et al. Leukocytes as a reservoir of circulating oncogenic DNA and regulatory targets of tumor-derived extracellular vesicles. J Thromb Haemost. 2018;16(9):1800-1813. doi:10.1111/jth.14222

145. Chen G, Huang AC, Zhang W, et al. Exosomal PD-L1 contributes to immunosuppression and is associated with anti-PD-1 response. Nature. 2018;560(7718):382-386. doi:10.1038/s41586-018-0392-8

146. Ning Y, Shen K, Wu Q, et al. Tumor exosomes block dendritic cells maturation to decrease the $\mathrm{T}$ cell immune response. Immunol Lett. 2018;199:36-43. doi:10.1016/j.imlet.2018.05.002

147. Wang W, Lotze MT. Good things come in small packages: exosomes, immunity and cancer. Cancer Gene Ther. 2014;21 (4):139-141. doi:10.1038/cgt.2014.14

148. Scrivo R, Vasile M, Bartosiewicz I, Valesini G. Inflammation as "common soil" of the multifactorial diseases. Autoimmun Rev. 2011;10(7):369-374. doi:10.1016/j.autrev.2010.12.006 
149. Sugimoto MA, Sousa LP, Pinho V, Perretti M, Teixeira MM. Resolution of inflammation: what controls its onset? Front Immunol. 2016;7:160. doi:10.3389/fimmu.2016.00160

150. Vlassov AV, Magdaleno S, Setterquist R, Conrad R. Exosomes: current knowledge of their composition, biological functions, and diagnostic and therapeutic potentials. Biochim Biophys Acta. 2012;1820(7):940-948. doi:10.1016/j.bbagen.2012.03.017

151. Fevrier B, Vilette D, Archer F, et al. Cells release prions in association with exosomes. Proc Natl Acad Sci U S A. 2004;101 (26):9683-9688. doi:10.1073/pnas.0308413101

152. Camussi G, Deregibus MC, Bruno S, Grange C, Fonsato V, Tetta C. Exosome/microvesicle-mediated epigenetic reprogramming of cells. Am J Cancer Res. 2011;1(1):98-110.

153. Lee Y, El Andaloussi S, Wood MJ. Exosomes and microvesicles: extracellular vesicles for genetic information transfer and gene therapy. Hum Mol Genet. 2012;21(R1):R125-R134. doi:10.1093/ hmg/dds 317

154. Sprent J. Swapping molecules during cell-cell interactions. Sci STKE. 2005;2005(273):pe8. doi:10.1126/stke.2732005pe8

155. Qazi KR, Gehrmann U, Domange Jordö E, Karlsson MC, Gabrielsson S. Antigen-loaded exosomes alone induce Th1-type memory through a B-cell-dependent mechanism. Blood. 2009;113 (12):2673-2683. doi:10.1182/blood-2008-04-153536

156. Muller L, Mitsuhashi M, Simms P, Gooding WE, Whiteside TL. Tumor-derived exosomes regulate expression of immune function-related genes in human $\mathrm{T}$ cell subsets. Sci Rep. 2016;6:20254. doi:10.1038/srep20254

157. Greening DW, Gopal SK, Xu R, Simpson RJ, Chen W. Exosomes and their roles in immune regulation and cancer. Semin Cell Dev Biol. 2015;40:72-81. doi:10.1016/j.semcdb.2015.02.009

158. Chaput N, Théry C. Exosomes: immune properties and potential clinical implementations. Semin Immunopathol. 2011;33 (5):419-440. doi:10.1007/s00281-010-0233-9

159. Okoye IS, Coomes SM, Pelly VS, et al. MicroRNA-containing T-regulatory-cell-derived exosomes suppress pathogenic $\mathrm{T}$ helper 1 cells. Immunity. 2014;41(1):89-103. doi:10.1016/j.immuni.2014.05.019

160. Balusu S, Van Wonterghem E, De Rycke R, et al. Identification of a novel mechanism of blood-brain communication during peripheral inflammation via choroid plexus-derived extracellular vesicles. EMBO Mol Med. 2016;8(10):1162-1183. doi:10.15252/ emmm.201606271

161. Li X, Liu L, Yang J, et al. Exosome derived from human umbilical cord mesenchymal stem cell mediates MiR-181c attenuating burn-induced excessive inflammation. EBioMedicine. 2016;8:72-82. doi:10.1016/j.ebiom.2016.04.030

162. Alexander M, Ramstead AG, Bauer KM, et al. Rab27-dependent exosome production inhibits chronic inflammation and enables acute responses to inflammatory stimuli. J Immunol. 2017;199 (10):3559-3570. doi:10.4049/jimmunol.1700904

163. Tung SL, Boardman DA, Sen M, et al. Regulatory T cell-derived extracellular vesicles modify dendritic cell function. Sci Rep. 2018;8(1):6065. doi:10.1038/s41598-018-24531-8

164. Zhang A, Wang G, Jia L, Su T, Zhang L. Exosome-mediated microRNA-138 and vascular endothelial growth factor in endometriosis through inflammation and apoptosis via the nuclear factor- $\mathrm{B}$ signaling pathway. Int $J$ Mol Med. 2019;43 (1):358-370. doi:10.3892/ijmm.2018.3980

165. Li ZL, Lv LL, Tang TT, et al. HIF-1 $\alpha$ inducing exosomal microRNA23a expression mediates the cross-talk between tubular epithelial cells and macrophages in tubulointerstitial inflammation. Kidney Int. 2019;95(2):388-404. doi:10.1016/j.kint.2018.09.013

166. Liu W, Yu M, Xie D, et al. Melatonin-stimulated MSC-derived exosomes improve diabetic wound healing through regulating macrophage M1 and M2 polarization by targeting the PTEN/ AKT pathway. Stem Cell Res Ther. 2020;11(1):259. doi:10.1186/s13287-020-01756-x
167. Song P, Li W, Xie J, Hou Y, You C. Cytokine storm induced by SARS-CoV-2. Clin Chim Acta. 2020;509:280-287. doi:10.1016/j. cca.2020.06.017

168. Bulut Ö, GÜrsel İ. Mesenchymal stem cell derived extracellular vesicles: promising immunomodulators against autoimmune, autoinflammatory disorders and SARS-CoV-2 infection. Turk $J$ Biol. 2020;44(3):273-282. doi:10.3906/biy-2002-79

169. Xin L, Lin X, Zhou F, et al. A scaffold laden with mesenchymal stem cell-derived exosomes for promoting endometrium regeneration and fertility restoration through macrophage immunomodulation. Acta Biomater. 2020;113:252-266. doi:10.1016/j.actbio.2020.06.029

170. Bedford JG, Infusini G, Dagley LF, et al. Airway exosomes released during influenza virus infection serve as a key component of the antiviral innate immune response. Front Immunol. 2020;11:887. doi:10.3389/fimmu.2020.00887

171. Shenoy GN, Loyall J, Maguire O, et al. Exosomes associated with human ovarian tumors harbor a reversible checkpoint of T-cell responses. Cancer Immunol Res. 2018;6(2):236-247. doi:10.1158/2326-6066.Cir-17-0113

172. Ke Y, Fan X, Rui H, et al. Exosomes derived from RPE cells under oxidative stress mediate inflammation and apoptosis of normal RPE cells through Apaf1/caspase-9 axis. $J$ Cell Biochem. 2020;121(12):4849-4861. doi:10.1002/jcb.29713

173. Xu J, Camfield R, Gorski SM. The interplay between exosomes and autophagy - partners in crime. J Cell Sci. 2018;131(15): jcs215210. doi:10.1242/jcs. 215210

174. Collado M, Serrano M. Senescence in tumours: evidence from mice and humans. Nat Rev Cancer. 2010;10(1):51-57. doi: $10.1038 / \mathrm{nrc} 2772$

175. Kuilman T, Michaloglou C, Mooi WJ, Peeper DS. The essence of senescence. Genes Dev. 2010;24(22):2463-2479. doi:10.1101/ gad. 1971610

176. Baixauli F, López-Otín C, Mittelbrunn M. Exosomes and autophagy: coordinated mechanisms for the maintenance of cellular fitness. Front Immunol. 2014;5:403. doi:10.3389/ fimmu.2014.00403

177. Conner SD, Schmid SL. Regulated portals of entry into the cell. Nature. 2003;422(6927):37-44. doi:10.1038/nature01451

178. Tokarev AA, Alfonso A, Segev N. Overview of intracellular compartments and trafficking pathways. In: Trafficking Inside Cells: Pathways, Mechanisms and Regulation, edited by Nava Segev, Editor, with Associate Editors: Aixa Alfonso, Gregory Payne and Julie Donaldson. Springer; 2009:3-14.

179. Bareford LM, Swaan PW. Endocytic mechanisms for targeted drug delivery. Adv Drug Deliv Rev. 2007;59(8):748-758. doi:10.1016/j.addr.2007.06.008

180. Klionsky DJ, Emr SD. Autophagy as a regulated pathway of cellular degradation. Science. 2000;290(5497):1717-1721. doi:10.1126/science.290.5497.1717

181. Dupont N, Jiang S, Pilli M, Ornatowski W, Bhattacharya D, Deretic V. Autophagy-based unconventional secretory pathway for extracellular delivery of IL-1ß. EMBO J. 2011;30 (23):4701-4711. doi:10.1038/emboj.2011.398

182. Takahashi H, Inoue J, Sakaguchi K, Takagi M, Mizutani S, Inazawa J. Autophagy is required for cell survival under L-asparaginase-induced metabolic stress in acute lymphoblastic leukemia cells. Oncogene. 2017;36(30):4267-4276. doi:10.1038/ onc.2017.59

183. Maes H, Kuchnio A, Peric A, et al. Tumor vessel normalization by chloroquine independent of autophagy. Cancer Cell. 2014;26 (2):190-206. doi:10.1016/j.ccr.2014.06.025

184. Salomon C, Rice GE. Role of exosomes in placental homeostasis and pregnancy disorders. Prog Mol Biol Transl Sci. 2017;145:163-179. doi:10.1016/bs.pmbts.2016.12.006 
185. Rink J, Ghigo E, Kalaidzidis Y, Zerial M. Rab conversion as a mechanism of progression from early to late endosomes. Cell. 2005;122(5):735-749. doi:10.1016/j.cell.2005.06.043

186. Hanson PI, Cashikar A. Multivesicular body morphogenesis. Annu Rev Cell Dev Biol. 2012;28:337-362. doi:10.1146/annurevcellbio-092910-154152

187. Bari R, Guo Q, Xia B, et al. Tetraspanins regulate the protrusive activities of cell membrane. Biochem Biophys Res Commun. 2011;415(4):619-626. doi:10.1016/j.bbrc.2011.10.121

188. Huotari J, Helenius A. Endosome maturation. EMBO J. 2011;30 (17):3481-3500. doi:10.1038/emboj.2011.286

189. Perez-Hernandez D, Gutiérrez-Vázquez C, Jorge I, et al. The intracellular interactome of tetraspanin-enriched microdomains reveals their function as sorting machineries toward exosomes. $J$ Biol Chem. 2013;288(17):11649-11661. doi:10.1074/jbc. M112.445304

190. Edgar JR, Eden ER, Futter CE. Hrs- and CD63-dependent competing mechanisms make different sized endosomal intraluminal vesicles. Traffic. 2014;15(2):197-211. doi:10.1111/tra.12139

191. Batagov AO, Kuznetsov VA, Kurochkin IV. Identification of nucleotide patterns enriched in secreted RNAs as putative cis-acting elements targeting them to exosome nano-vesicles. BMC Genomics. 2011;12 Suppl 3(Supp13):S18. doi:10.1186/ 1471-2164-12-s3-s18

192. van Balkom BW, Eisele AS, Pegtel DM, Bervoets S, Verhaar MC. Quantitative and qualitative analysis of small RNAs in human endothelial cells and exosomes provides insights into localized RNA processing, degradation and sorting. J Extracell Vesicles. 2015;4:26760. doi:10.3402/jev.v4.26760

193. Zhu Y, Chen X, Pan Q, et al. A comprehensive proteomics analysis reveals a secretory path- and status-dependent signature of exosomes released from tumor-associated macrophages. J Proteome Res. 2015;14(10):4319-4331. doi:10.1021/acs. jproteome.5b00770

194. Strauss K, Goebel C, Runz H, et al. Exosome secretion ameliorates lysosomal storage of cholesterol in Niemann-Pick type C disease. J Biol Chem. 2010;285(34):26279-26288. doi:10.1074/ jbc.M110.134775

195. Ojha CR, Lapierre J, Rodriguez M, et al. Interplay between autophagy, exosomes and HIV-1 associated neurological disorders: new insights for diagnosis and therapeutic applications. Viruses. 2017;9(7):176. doi:10.3390/v9070176

196. Murrow L, Malhotra R, Debnath J. ATG12-ATG3 interacts with Alix to promote basal autophagic flux and late endosome function. Nat Cell Biol. 2015;17(3):300-310. doi:10.1038/ncb3112

197. Kalra H, Simpson RJ, Ji H, et al. Vesiclepedia: a compendium for extracellular vesicles with continuous community annotation. PLoS Biol. 2012;10(12):e1001450. doi:10.1371/journal.pbio.1001450

198. Galluzzi L, Green DR. Autophagy-independent functions of the autophagy machinery. Cell. 2019;177(7):1682-1699. doi:10.1016/j.cell.2019.05.026

199. Fader CM, Sánchez D, Furlán M, Colombo MI. Induction of autophagy promotes fusion of multivesicular bodies with autophagic vacuoles in k562 cells. Traffic. 2008;9(2):230-250. doi:10.1111/j.1600-0854.2007.00677.x

200. Sahu R, Kaushik S, Clement CC, et al. Microautophagy of cytosolic proteins by late endosomes. Dev Cell. 2011;20(1):131-139. doi:10.1016/j.devcel.2010.12.003

201. Patel KK, Miyoshi H, Beatty WL, et al. Autophagy proteins control goblet cell function by potentiating reactive oxygen species production. EMBO J. 2013;32(24):3130-3144. doi:10.1038/ emboj.2013.233

202. Ponpuak M, Mandell MA, Kimura T, Chauhan S, Cleyrat C, Deretic V. Secretory autophagy. Curr Opin Cell Biol. 2015;35:106-116. doi:10.1016/j.ceb.2015.04.016
203. Griffiths RE, Kupzig S, Cogan N, et al. Maturing reticulocytes internalize plasma membrane in glycophorin A-containing vesicles that fuse with autophagosomes before exocytosis. Blood. 2012;119(26):6296-6306. doi:10.1182/ blood-2011-09-376475

204. Li B, Lu Y, Wang H, et al. miR-221/222 enhance the tumorigenicity of human breast cancer stem cells via modulation of PTEN/ Akt pathway. Biomed Pharmacother. 2016;79:93-101. doi:10.1016/j.biopha.2016.01.045

205. Liu X, Deng Y, Xu Y, Jin W, Li H. MicroRNA-223 protects neonatal rat cardiomyocytes and $\mathrm{H} 9 \mathrm{c} 2$ cells from hypoxia-induced apoptosis and excessive autophagy via the Akt/ mTOR pathway by targeting PARP-1. J Mol Cell Cardiol. 2018;118:133-146. doi:10.1016/j.yjmcc.2018.03.018

206. Li T, Gu J, Yang O, Wang J, Wang Y, Kong J. Bone marrow mesenchymal stem cell-derived exosomal miRNA-29c decreases cardiac ischemia/reperfusion injury through inhibition of excessive autophagy via the PTEN/Akt/mTOR signaling pathway. Circ J. 2020;84(8):1304-1311. doi:10.1253/circj.CJ-19-1060

207. He Q, Wang L, Zhao R, et al. Mesenchymal stem cell-derived exosomes exert ameliorative effects in type 2 diabetes by improving hepatic glucose and lipid metabolism via enhancing autophagy. Stem Cell Res Ther. 2020;11(1):223. doi:10.1186/ s13287-020-01731-6

208. Zhu M, Liu X, Li W, Wang L. Exosomes derived from mmu_circ_0000623-modified ADSCs prevent liver fibrosis via activating autophagy. Hum Exp Toxicol. 2020;39 (12):1619-1627. doi:10.1177/0960327120931152

209. Gao J, Wei B, de Assuncao TM, et al. Hepatic stellate cell autophagy inhibits extracellular vesicle release to attenuate liver fibrosis. $J$ Hepatol. 2020;73(5):1144-1154. doi:10.1016/j. jhep.2020.04.044

210. Shi R, Jin $\mathrm{Y}$, $\mathrm{Hu} \mathrm{W}$, et al. Exosomes derived from mmu circ 0000250-modified adipose-derived mesenchymal stem cells promote wound healing in diabetic mice by inducing miR-128-3p/SIRT1-mediated autophagy. Am J Physiol Cell Physiol. 2020;318(5):C848-C856. doi:10.1152/ajpcell.000 41.2020

211. Santoso MR, Ikeda G, Tada Y, et al. Exosomes from induced pluripotent stem cell-derived cardiomyocytes promote autophagy for myocardial repair. J Am Heart Assoc. 2020;9(6):e014345. doi:10.1161/jaha.119.014345

212. Yang B, Duan W, Wei L, et al. Bone marrow mesenchymal stem cell-derived hepatocyte-like cell exosomes reduce hepatic ischemia/reperfusion injury by enhancing autophagy. Stem Cells Dev. 2020;29(6):372-379. doi:10.1089/scd.2019.0194

213. Meckes DG Jr, Raab-Traub N. Microvesicles and viral infection. $J$ Virol. 2011;85(24):12844-12854. doi:10.1128/jvi.05853-11

214. Alenquer M, Amorim MJ. Exosome biogenesis, regulation, and function in viral infection. Viruses. 2015;7(9):5066-5083. doi: $10.3390 / \mathrm{v} 7092862$

215. Chahar HS, Bao X, Casola A. Exosomes and their role in the life cycle and pathogenesis of RNA viruses. Viruses. 2015;7 (6):3204-3225. doi: $10.3390 / \mathrm{v} 7062770$

216. Nolte-'t Hoen E, Cremer T, Gallo RC, Margolis LB. Extracellular vesicles and viruses: are they close relatives? Proc Natl Acad Sci $U$ S A. 2016;113(33):9155-9161. doi:10.1073/pnas.1605146113

217. Anderson MR, Kashanchi F, Jacobson S. Exosomes in viral disease. Neurotherapeutics. 2016;13(3):535-546. doi:10.1007/ s13311-016-0450-6

218. Raab-Traub N, Dittmer DP. Viral effects on the content and function of extracellular vesicles. Nat Rev Microbiol. 2017;15 (9):559-572. doi:10.1038/nrmicro.2017.60 
219. Munich S, Sobo-Vujanovic A, Buchser WJ, Beer-Stolz D, Vujanovic NL. Dendritic cell exosomes directly kill tumor cells and activate natural killer cells via TNF superfamily ligands. Oncoimmunology. 2012;1(7):1074-1083. doi:10.4161/onci.20897

220. Tian T, Zhu YL, Hu FH, Wang YY, Huang NP, Xiao ZD. Dynamics of exosome internalization and trafficking. $J$ Cell Physiol. 2013;228(7):1487-1495. doi:10.1002/jcp.24304

221. Mulcahy LA, Pink RC, Carter DR. Routes and mechanisms of extracellular vesicle uptake. J Extracell Vesicles. 2014;3:24641. doi:10.3402/jev.v3.24641

222. Madison MN, Okeoma CM. Exosomes: implications in HIV-1 pathogenesis. Viruses. 2015;7(7):4093-4118. doi:10.3390/ v7072810

223. Sims B, Farrow AL, Williams SD, Bansal A, Krendelchtchikov A, Matthews QL. Tetraspanin blockage reduces exosome-mediated HIV-1 entry. Arch Virol. 2018;163 (6):1683-1689. doi:10.1007/s00705-018-3737-6

224. Maemura T, Fukuyama S, Kawaoka Y. High levels of miR-483$3 \mathrm{p}$ are present in serum exosomes upon infection of mice with highly pathogenic avian influenza virus. Front Microbiol. 2020;11:144. doi:10.3389/fmicb.2020.00144

225. Chen J, Xu Q, Zhang Y, Zhang H. RNA profiling analysis of the serum exosomes derived from patients with chronic hepatitis and acute-on-chronic liver failure caused by HBV. Sci Rep. 2020;10 (1):1528. doi:10.1038/s41598-020-58233-x

226. Zhou W, Woodson M, Sherman MB, Neelakanta G, Sultana H. Exosomes mediate Zika virus transmission through SMPD3 neutral Sphingomyelinase in cortical neurons. Emerg Microbes Infect. 2019;8(1):307-326. doi:10.1080/22221751.2019.1578188

227. Smit JM, Moesker B, Rodenhuis-Zybert I, Wilschut J. Flavivirus cell entry and membrane fusion. Viruses. 2011;3(2):160-171. doi: 10.3390/v3020160

228. Ramakrishnaiah V, Thumann C, Fofana I, et al. Exosomemediated transmission of hepatitis $\mathrm{C}$ virus between human hepatoma Huh7.5 cells. Proc Natl Acad Sci U S A. 2013;110 (32):13109-13113. doi:10.1073/pnas.1221899110

229. Nour AM, Modis Y. Endosomal vesicles as vehicles for viral genomes. Trends Cell Biol. 2014;24(8):449-454. doi:10.1016/j. tcb.2014.03.006

230. Hamel R, Dejarnac O, Wichit S, et al. Biology of Zika virus infection in human skin cells. J Virol. 2015;89(17):8880-8896. doi:10.1128/jvi.00354-15

231. Théry C, Boussac M, Véron P, et al. Proteomic analysis of dendritic cell-derived exosomes: a secreted subcellular compartment distinct from apoptotic vesicles. J Immunol. 2001;166 (12):7309-7318. doi:10.4049/jimmunol.166.12.7309

232. Conde-Vancells J, Rodriguez-Suarez E, Embade N, et al. Characterization and comprehensive proteome profiling of exosomes secreted by hepatocytes. J Proteome Res. 2008;7 (12):5157-5166. doi:10.1021/pr8004887

233. Ott DE. Cellular proteins detected in HIV-1. Rev Med Virol. 2008;18(3):159-175. doi:10.1002/rmv.570

234. Krishnamoorthy L, Bess JW Jr, Preston AB, Nagashima K, Mahal LK. HIV-1 and microvesicles from $\mathrm{T}$ cells share a common glycome, arguing for a common origin. Nat Chem Biol. 2009;5(4):244-250. doi:10.1038/nchembio.151

235. Lenassi M, Cagney G, Liao M, et al. HIV Nef is secreted in exosomes and triggers apoptosis in bystander CD4+ $\mathrm{T}$ cells. Traffic. 2010;11(1):110-122. doi:10.1111/j.1600-0854.200 9.01006.x

236. Pegtel DM, Cosmopoulos K, Thorley-Lawson DA, et al. Functional delivery of viral miRNAs via exosomes. Proc Natl Acad Sci U S A. 2010;107(14):6328-6333. doi:10.1073/ pnas.0914843107
237. Izquierdo-Useros N, Lorizate M, Puertas MC, et al. Siglec-1 is a novel dendritic cell receptor that mediates HIV-1 trans-infection through recognition of viral membrane gangliosides. PLoS Biol. 2012;10(12):e1001448. doi:10.1371/journal.pbio.1001448

238. Chen L, Feng $\mathrm{Z}$, Yue $\mathrm{H}$, et al. Exosomes derived from HIV-1-infected cells promote growth and progression of cancer via HIV TAR RNA. Nat Commun. 2018;9(1):4585. doi:10.1038/ s41467-018-07006-2

239. Pleet ML, Erickson J, DeMarino C, et al. Ebola virus VP40 modulates cell cycle and biogenesis of extracellular vesicles. J Infect Dis. 2018;218(suppl_5):S365-S387. doi:10.1093/infdis/ jiy472

240. Jemielity S, Wang JJ, Chan YK, et al. TIM-family proteins promote infection of multiple enveloped viruses through virion-associated phosphatidylserine. PLoS Pathog. 2013;9(3): e1003232. doi:10.1371/journal.ppat.1003232

241. Sims B, Farrow AL, Williams SD, et al. Role of TIM-4 in exosome-dependent entry of HIV-1 into human immune cells. Int $J$ Nanomedicine. 2017;12:4823-4833. doi:10.2147/ijn. S132762

242. Kalluri R, LeBleu VS. The biology, function, and biomedical applications of exosomes. Science. 2020;367(6478):eaau6977. doi:10.1126/science.aau6977

243. Jansen F, Li Q. Exosomes as diagnostic biomarkers in cardiovascular diseases. Adv Exp Med Biol. 2017;998:61-70. doi:10.1007/ 978-981-10-4397-0_4

244. Kanninen KM, Bister N, Koistinaho J, Malm T. Exosomes as new diagnostic tools in CNS diseases. Biochim Biophys Acta. 2016;1862(3):403-410. doi:10.1016/j.bbadis.2015.09.020

245. Fitts CA, Ji N, Li Y, Tan C. Exploiting exosomes in cancer liquid biopsies and drug delivery. Adv Healthc Mater. 2019;8(6): e1801268. doi:10.1002/adhm.201801268

246. Masyuk AI, Masyuk TV, Larusso NF. Exosomes in the pathogenesis, diagnostics and therapeutics of liver diseases. $J$ Hepatol. 2013;59(3):621-625. doi:10.1016/j.jhep.2013.03.028

247. Zhang W, Zhou X, Zhang H, Yao Q, Liu Y, Dong Z. Extracellular vesicles in diagnosis and therapy of kidney diseases. Am J Physiol Renal Physiol. 2016;311(5):F844-F851. doi:10.1152/ ajprenal.00429.2016

248. Alipoor SD, Mortaz E, Garssen J, Movassaghi M, Mirsaeidi M, Adcock IM. Exosomes and exosomal miRNA in respiratory diseases. Mediators Inflamm. 2016;2016:5628404. doi:10.1155/ 2016/5628404

249. Cai J, Han Y, Ren H, et al. Extracellular vesicle-mediated transfer of donor genomic DNA to recipient cells is a novel mechanism for genetic influence between cells. J Mol Cell Biol. 2013;5 (4):227-238. doi:10.1093/jmcb/mjt011

250. Cha DJ, Franklin JL, Dou Y, et al. KRAS-dependent sorting of miRNA to exosomes. Elife. 2015;4:e07197. doi:10.7554/ eLife.07197

251. Salehi M, Sharifi M. Exosomal miRNAs as novel cancer biomarkers: challenges and opportunities. J Cell Physiol. 2018;233 (9):6370-6380. doi:10.1002/jcp.26481

252. Thind A, Wilson C. Exosomal miRNAs as cancer biomarkers and therapeutic targets. $J$ Extracell Vesicles. 2016;5:31292. doi:10.3402/jev.v5.31292

253. Frampton AE, Prado MM, López-Jiménez E, et al. Glypican-1 is enriched in circulating-exosomes in pancreatic cancer and correlates with tumor burden. Oncotarget. 2018;9(27):19006-19013. doi:10.18632/oncotarget.24873

254. Melo SA, Luecke LB, Kahlert C, et al. Glypican-1 identifies cancer exosomes and detects early pancreatic cancer. Nature. 2015;523(7559):177-182. doi:10.1038/nature14581 
255. LeBleu VS, Kalluri R. Exosomes as a multicomponent biomarker platform in cancer. Trends Cancer. 2020;6(9):767-774. doi:10.1016/j.trecan.2020.03.007

256. Whiteside TL. Tumor-derived exosomes and their role in cancer progression. Adv Clin Chem. 2016;74:103-141. doi:10.1016/bs. acc.2015.12.005

257. Allenson K, Castillo J, San Lucas FA, et al. High prevalence of mutant KRAS in circulating exosome-derived DNA from early-stage pancreatic cancer patients. Ann Oncol. 2017;28 (4):741-747. doi:10.1093/annonc/mdx004

258. Prendergast EN, de Souza Fonseca MA, Dezem FS, et al. Optimizing exosomal RNA isolation for RNA-Seq analyses of archival sera specimens. PLoS One. 2018;13(5):e0196913. doi:10.1371/journal.pone.0196913

259. Zhang Y, Han T, Feng D, et al. Screening of non-invasive miRNA biomarker candidates for metastasis of gastric cancer by small RNA sequencing of plasma exosomes. Carcinogenesis. 2020;41 (5):582-590. doi:10.1093/carcin/bgz186

260. Kato T, Mizutani K, Kawakami K, Fujita Y, Ehara H, Ito M. CD44v8-10 mRNA contained in serum exosomes as a diagnostic marker for docetaxel resistance in prostate cancer patients. Heliyon. 2020;6(7):e04138. doi:10.1016/j.heliyon.2020.e04138

261. Li W, Dong Y, Wang KJ, Deng Z, Zhang W, Shen HF. Plasma exosomal miR-125a-5p and miR-141-5p as non-invasive biomarkers for prostate cancer. Neoplasma. 2020. doi:10.4149/ neo $2020 \quad 191130$ N1234

262. Zhou H, Shen W, Zou H, Lv Q, Shao P. Circulating exosomal long non-coding RNA H19 as a potential novel diagnostic and prognostic biomarker for gastric cancer. J Int Med Res. 2020;48 (7):300060520934297. doi:10.1177/0300060520934297

263. Jiao Z, Yu A, Rong W, et al. Five-lncRNA signature in plasma exosomes serves as diagnostic biomarker for esophageal squamous cell carcinoma. Aging (Albany NY). 2020;12 (14):15002-15010. doi:10.18632/aging.103559

264. Yao Z, Jia C, Tai Y, et al. Serum exosomal long noncoding RNAs lnc-FAM72D-3 and lnc-EPC1-4 as diagnostic biomarkers for hepatocellular carcinoma. Aging (Albany NY). 2020;12 (12):11843-11863. doi:10.18632/aging.103355

265. Xian J, Su W, Liu L, et al. Identification of three circular RNA cargoes in serum exosomes as diagnostic biomarkers of non-small-cell lung cancer in the chinese population. $J \mathrm{Mol}$ Diagn. 2020;22(8):1096-1108. doi:10.1016/j.jmoldx.2020.05.011

266. Ling H, Guo Z, Shi Y, Zhang L, Song C. Serum exosomal MicroRNA-21, MicroRNA-126, and PTEN are novel biomarkers for diagnosis of acute coronary syndrome. Front Physiol. 2020;11:654. doi:10.3389/fphys.2020.00654

267. Xu Z, Wang Z, Sun H, Xin H. Evaluation of exosomal miRNA in blood as a potential diagnostic biomarker for human non-small cell lung cancer. Med Sci Monit. 2020;26:e924721. doi:10.12659/ msm.924721

268. Zöller M. Tetraspanins: push and pull in suppressing and promoting metastasis. Nat Rev Cancer. 2009;9(1):40-55. doi:10.1038/ nrc2543

269. Pap E, Pállinger E, Pásztói M, Falus A. Highlights of a new type of intercellular communication: microvesicle-based information transfer. Inflamm Res. 2009;58(1):1-8. doi:10.1007/s00011-0088210-7

270. Andre F, Schartz NE, Movassagh M, et al. Malignant effusions and immunogenic tumour-derived exosomes. Lancet. 2002;360 (9329):295-305. doi:10.1016/s0140-6736(02)09552-1

271. Amigorena S. Anti-tumour immunotherapy using dendritic-cellderived exosomes. Res Immunol. 1998;149(7-8):661-662. doi:10.1016/s0923-2494(99)80035-2
272. Hsu M, Zhang J, Flint M, et al. Hepatitis C virus glycoproteins mediate $\mathrm{pH}$-dependent cell entry of pseudotyped retroviral particles. Proc Natl Acad Sci U S A. 2003;100(12):7271-7276. doi:10.1073/pnas.0832180100

273. Baglio SR, Pegtel DM, Baldini N. Mesenchymal stem cell secreted vesicles provide novel opportunities in (stem) cell-free therapy. Front Physiol. 2012;3:359. doi:10.3389/ fphys.2012.00359

274. Chen J, Liu Z, Hong MM, et al. Proangiogenic compositions of microvesicles derived from human umbilical cord mesenchymal stem cells. PLoS One. 2014;9(12):e115316. doi:10.1371/journal. pone. 0115316

275. Lee C, Mitsialis SA, Aslam M, et al. Exosomes mediate the cytoprotective action of mesenchymal stromal cells on hypoxia-induced pulmonary hypertension. Circulation. 2012;126 (22):2601-2611. doi:10.1161/circulationaha.112.114173

276. Doeppner TR, Herz J, Görgens A, et al. Extracellular vesicles improve post-stroke neuroregeneration and prevent postischemic immunosuppression. Stem Cells Transl Med. 2015;4 (10):1131-1143. doi:10.5966/sctm.2015-0078

277. Zhang Y, Chopp M, Meng Y, et al. Effect of exosomes derived from multipluripotent mesenchymal stromal cells on functional recovery and neurovascular plasticity in rats after traumatic brain injury. JNeurosurg. 2015;122(4):856-867. doi:10.3171/2014.11.Jns14770

278. Lee JK, Park SR, Jung BK, et al. Exosomes derived from mesenchymal stem cells suppress angiogenesis by down-regulating VEGF expression in breast cancer cells. PLoS One. 2013;8(12):e84256. doi:10.1371/journal. pone.0084256

279. Kordelas L, Rebmann V, Ludwig AK, et al. MSC-derived exosomes: a novel tool to treat therapy-refractory graft-versus-host disease. Leukemia. 2014;28(4):970-973. doi:10.1038/leu.2014.41

280. Ohno S, Takanashi M, Sudo K, et al. Systemically injected exosomes targeted to EGFR deliver antitumor microRNA to breast cancer cells. Mol Ther. 2013;21(1):185-191. doi:10.1038/mt.2012.180

281. Katakowski M, Buller B, Zheng X, et al. Exosomes from marrow stromal cells expressing miR-146b inhibit glioma growth. Cancer Lett. 2013;335(1):201-204. doi:10.1016/j.canlet.2013.02.019

282. Alvarez-Erviti L, Seow Y, Yin H, Betts C, Lakhal S, Wood MJ. Delivery of siRNA to the mouse brain by systemic injection of targeted exosomes. Nat Biotechnol. 2011;29(4):341-345. doi:10.1038/nbt.1807

283. Kantoff PW, Schuetz TJ, Blumenstein BA, et al. Overall survival analysis of a Phase II randomized controlled trial of a Poxviral-based PSA-targeted immunotherapy in metastatic castration-resistant prostate cancer. J Clin Oncol. 2010;28 (7):1099-1105. doi:10.1200/jco.2009.25.0597

284. Besse B, Charrier M, Lapierre V, et al. Dendritic cell-derived exosomes as maintenance immunotherapy after first line chemotherapy in NSCLC. Oncoimmunology. 2016;5(4):e1071008. doi:10.1080/2162402x.2015.1071008

285. Lee M, Liu T, Im W, Kim M. Exosomes from adipose-derived stem cells ameliorate phenotype of Huntington's disease in vitro model. Eur J Neurosci. 2016;44(4):2114-2119. doi:10.1111/ ejn. 13275

286. Sun D, Zhuang X, Xiang X, et al. A novel nanoparticle drug delivery system: the anti-inflammatory activity of curcumin is enhanced when encapsulated in exosomes. Mol Ther. 2010;18 (9):1606-1614. doi:10.1038/mt.2010.105

287. Kooijmans SA, Vader P, van Dommelen SM, van Solinge WW, Schiffelers RM. Exosome mimetics: a novel class of drug delivery systems. Int $J$ Nanomedicine. 2012;7:1525-1541. doi:10.2147/ijn.S29661 
288. Turturici G, Tinnirello R, Sconzo G, Geraci F. Extracellular membrane vesicles as a mechanism of cell-to-cell communication: advantages and disadvantages. Am J Physiol Cell Physiol. 2014;306(7):C621-C633. doi:10.1152/ajpcell.00228.2013

289. Barile L, Vassalli G. Exosomes: therapy delivery tools and biomarkers of diseases. Pharmacol Ther. 2017;174:63-78. doi:10.1016/j.pharmthera.2017.02.020

290. Liao W, Du Y, Zhang C, et al. Exosomes: the next generation of endogenous nanomaterials for advanced drug delivery and therapy. Acta Biomater. 2019;86:1-14. doi:10.1016/j. actbio.2018.12.045

291. Williams AM, Dennahy IS, Bhatti UF, et al. Mesenchymal stem cell-derived exosomes provide neuroprotection and improve long-term neurologic outcomes in a swine model of traumatic brain injury and hemorrhagic shock. J Neurotrauma. 2019;36 (1):54-60. doi:10.1089/neu.2018.5711

292. Du Y, Li D, Han C, et al. Exosomes from human-induced pluripotent stem cell-derived mesenchymal stromal cells (hiPSC-MSCs) protect liver against hepatic ischemia/reperfusion injury via activating sphingosine Kinase and sphingosine-1-phosphate signaling pathway. Cell Physiol Biochem. 2017;43(2):611-625. doi:10.1159/000480533

293. Qu M, Lin Q, Huang L, et al. Dopamine-loaded blood exosomes targeted to brain for better treatment of Parkinson's disease. $J$ Control Release. 2018;287:156-166. doi:10.1016/j. jconrel.2018.08.035

294. Li YJ, Wu JY, Wang JM, Hu XB, Cai JX, Xiang DX. Gemcitabine loaded autologous exosomes for effective and safe chemotherapy of pancreatic cancer. Acta Biomater. 2020;101:519-530. doi:10.1016/j.actbio.2019.10.022

295. Cooper JM, Wiklander PB, Nordin JZ, et al. Systemic exosomal siRNA delivery reduced alpha-synuclein aggregates in brains of transgenic mice. Mov Disord. 2014;29(12):1476-1485. doi: $10.1002 / \mathrm{mds} .25978$

296. Murphy DE, de Jong OG, Brouwer M, et al. Extracellular vesicle-based therapeutics: natural versus engineered targeting and trafficking. Exp Mol Med. 2019;51(3):1-12. doi:10.1038/ s12276-019-0223-5

297. Liu Y, Gu Y, Cao X. The exosomes in tumor immunity. Oncoimmunology. 2015;4(9):e1027472. doi:10.1080/ 2162402x.2015.1027472

298. Rana S, Yue S, Stadel D, Zöller M. Toward tailored exosomes: the exosomal tetraspanin web contributes to target cell selection. Int J Biochem Cell Biol. 2012;44(9):1574-1584. doi:10.1016/j. biocel.2012.06.018

299. Matsumoto A, Takahashi Y, Nishikawa M, et al. Role of phosphatidylserine-derived negative surface charges in the recognition and uptake of intravenously injected B16BL6-derived exosomes by macrophages. J Pharm Sci. 2017;106(1):168-175. doi:10.1016/j.xphs.2016.07.022

300. Heath N, Osteikoetxea X, de Oliveria TM, et al. Endosomal escape enhancing compounds facilitate functional delivery of extracellular vesicle cargo. Nanomedicine (Lond). 2019;14 (21):2799-2814. doi:10.2217/nnm-2019-0061

301. Mentkowski KI, Lang JK. Exosomes engineered to express a cardiomyocyte binding peptide demonstrate improved cardiac retention in vivo. Sci Rep. 2019;9(1):10041. doi:10.1038/s41598019-46407-1

302. Izco M, Blesa J, Schleef M, et al. Systemic exosomal delivery of shRNA minicircles prevents parkinsonian pathology. Mol Ther. 2019;27(12):2111-2122. doi:10.1016/j.ymthe.2019.08.010

303. Zhang X, Liu L, Tang M, Li H, Guo X, Yang X. The effects of umbilical cord-derived macrophage exosomes loaded with cisplatin on the growth and drug resistance of ovarian cancer cells. Drug Dev Ind Pharm. 2020;46(7):1150-1162. doi:10.1080/ 03639045.2020.1776320
304. Shandilya S, Rani P, Onteru SK, Singh D. Natural ligand-receptor mediated loading of siRNA in milk derived exosomes. J Biotechnol. 2020;318:1-9. doi:10.1016/j.jbiotec.2020.04.015

305. Xin L, Yuan YW, Liu C, et al. Preparation of internalizing RGD-modified recombinant methioninase exosome active targeting vector and antitumor effect evaluation. Dig Dis Sci. 2020. doi:10.1007/s10620-020-06262-x

306. Choi H, Kim Y, Mirzaaghasi A, et al. Exosome-based delivery of super-repressor I $\mathrm{B} \mathrm{B} \alpha$ relieves sepsis-associated organ damage and mortality. Sci $A d v$. 2020;6(15):eaaz6980. doi:10.1126/sciadv. aaz6980

307. Nie S, Wang Z, Moscoso-Castro M, et al. Biology drives the discovery of bispecific antibodies as innovative therapeutics. Antib Ther. 2020;3(1):18-62. doi:10.1093/abt/tbaa003

308. Zhang Z, Dombroski JA, King MR. Engineering of exosomes to target cancer metastasis. Cell Mol Bioeng. 2020;13(1):1-16. doi:10.1007/s12195-019-00607-x

309. Yu M, Gai C, Li Z, et al. Targeted exosome-encapsulated erastin induced ferroptosis in triple negative breast cancer cells. Cancer Sci. 2019;110(10):3173-3182. doi:10.1111/cas.14181

310. Qi Y, Guo L, Jiang Y, Shi Y, Sui H, Zhao L. Brain delivery of quercetin-loaded exosomes improved cognitive function in $\mathrm{AD}$ mice by inhibiting phosphorylated tau-mediated neurofibrillary tangles. Drug Deliv. 2020;27(1):745-755. doi:10.1080/ 10717544.2020.1762262

311. Fan Y, Li Y, Huang S, Xu H, Li H, Liu B. Resveratrol-primed exosomes strongly promote the recovery of motor function in SCI rats by activating autophagy and inhibiting apoptosis via the PI3K signaling pathway. Neurosci Lett. 2020;736:135262. doi:10.1016/ j.neulet.2020.135262

312. Yao S, Yin Y, Jin G, et al. Exosome-mediated delivery of miR-204-5p inhibits tumor growth and chemoresistance. Cancer Med. 2020. doi:10.1002/cam4.3248

313. Yang J, Wu S, Hou L, et al. Therapeutic effects of simultaneous delivery of nerve growth factor mRNA and protein via exosomes on cerebral ischemia. Mol Ther Nucleic Acids. 2020;21:512-522. doi:10.1016/j.omtn.2020.06.013

314. Losurdo M, Pedrazzoli M, D'Agostino C, et al. Intranasal delivery of mesenchymal stem cell-derived extracellular vesicles exerts immunomodulatory and neuroprotective effects in a $3 \times \mathrm{Tg}$ model of Alzheimer's disease. Stem Cells Transl Med. 2020. doi:10.1002/sctm.19-0327

315. Kim MS, Haney MJ, Zhao Y, et al. Development of exosome-encapsulated paclitaxel to overcome MDR in cancer cells. Nanomedicine. 2016;12(3):655-664. doi:10.1016/j. nano.2015.10.012

316. Saari H, Lázaro-Ibáñez E, Viitala T, Vuorimaa-Laukkanen E, Siljander P, Yliperttula M. Microvesicle- and exosome-mediated drug delivery enhances the cytotoxicity of Paclitaxel in autologous prostate cancer cells. J Control Release. 2015;220(Pt B):727-737. doi:10.1016/j.jconrel.2015.09.031

317. Hadla M, Palazzolo S, Corona G, et al. Exosomes increase the therapeutic index of doxorubicin in breast and ovarian cancer mouse models. Nanomedicine (Lond). 2016;11(18):2431-2441. doi:10.2217/nnm-2016-0154

318. Toffoli G, Hadla M, Corona G, et al. Exosomal doxorubicin reduces the cardiac toxicity of doxorubicin. Nanomedicine (Lond). 2015;10(19):2963-2971. doi:10.2217/nnm.15.118

319. Escudier B, Dorval T, Chaput N, et al. Vaccination of metastatic melanoma patients with autologous dendritic cell (DC) derived-exosomes: results of the first phase I clinical trial. $J$ Transl Med. 2005;3(1):10. doi:10.1186/1479-5876-3-10

320. Morse MA, Garst J, Osada T, et al. A phase I study of dexosome immunotherapy in patients with advanced non-small cell lung cancer. J Transl Med. 2005;3(1):9. doi:10.1186/1479-58763-9 
321. Li X, Corbett AL, Taatizadeh E, et al. Challenges and opportunities in exosome research-Perspectives from biology, engineering, and cancer therapy. APL Bioeng. 2019;3(1):011503. doi: $10.1063 / 1.5087122$

322. Chen YS, Lin EY, Chiou TW, Harn HJ. Exosomes in clinical trial and their production in compliance with good manufacturing practice. Ci Ji Yi Xue Za Zhi. 2020;32(2):113-120. doi:10.4103/ tcmj.tcmj_182_19
323. Dai S, Wei D, Wu Z, et al. Phase I clinical trial of autologous ascites-derived exosomes combined with GM-CSF for colorectal cancer. Mol Ther. 2008;16(4):782-790. doi:10.1038/mt.2008.1

324. Nassar W, El-Ansary M, Sabry D, et al. Umbilical cord mesenchymal stem cells derived extracellular vesicles can safely ameliorate the progression of chronic kidney diseases. Biomater Res. 2016;20:21. doi:10.1186/s40824-016-0068-0

\section{Publish your work in this journal}

The International Journal of Nanomedicine is an international, peerreviewed journal focusing on the application of nanotechnology in diagnostics, therapeutics, and drug delivery systems throughout the biomedical field. This journal is indexed on PubMed Central, MedLine, CAS, SciSearch ${ }^{\mathbb{R}}$, Current Contents ${ }^{\mathbb{R}} /$ Clinical Medicine, $^{2}$
Journal Citation Reports/Science Edition, EMBase, Scopus and the Elsevier Bibliographic databases. The manuscript management system is completely online and includes a very quick and fair peer-review system, which is all easy to use. Visit http://www.dovepress.com/ testimonials.php to read real quotes from published authors. 